\title{
A declustered earthquake catalog for the Iranian Plateau
}

\author{
Seyed Hasan Mousavi-Bafrouei, Noorbakhsh Mirzaei ${ }^{\star}$, Elham Shabani
}

University of Tehran, Institute of Geophysics, Department of Earth Physics, Tehran, Iran

\author{
Article history \\ Received August 13, 2013; accepted December 16, 2014. \\ Subject classification: \\ Uniform catalog, Completeness, Conversion relations, Declustering, Iran.
}

\begin{abstract}
A unified and a declustered catalog of earthquakes in Iran and adjacent regions (the area bounded in $22^{\circ}-42^{\circ} \mathrm{N}$ and $42^{\circ}-66^{\circ} \mathrm{E}$ ) covering the period of 4 th century B.C. through 2012 is provided. The catalog includes all events for which magnitude have been determined by international and local agencies and most reliable individual sources. Uncertainties of magnitude scales are estimated. Empirical formulae are established to convert magnitude scales using General Orthogonal Regression (GOR) method considering the estimated error variance ratio $\eta$. The results are compared to other regression methods e.g. SR, ISR and OR. The catalog is unified to $M_{w}$ and $M_{s}$ and the uncertainties of reported and converted $M_{w}$ are inserted the catalog. The unified catalog is declustered using conjugate distance-time windows. The magnitude of completeness $\left(M_{c}\right)$ is worked out by applying Entire-Magnitude-Range (EMR) method to the declustered catalog in each seismotectonic province. The $M_{c}$ decreases with development of local and regional seismic stations. The results of present study are particularly important in seismic hazard analysis in Iran.
\end{abstract}

\section{Introduction}

A homogenous earthquake catalog is a basic input for seismic hazard estimation and seismicity studies [e.g., Das et al. 2011]. A reliable homogeneous earthquake catalog with unified moment magnitude data, sufficiently low thresholds, covering the Iranian Plateau and long historical time spans up to recent times is an exigency. Recently, Shahvar et al. [2013] and Karimiparidari et al. [2013] published uniform earthquake catalogs for the Iranian Plateau. Mirzaei et al. [2014] discussed in details about the flaws of Shahvar et al. [2013]. Karimipridari et al. [2013] didn't clarify why data from different seismotectonic zones are merged to derive conversion relations.

In order to prepare homogeneous (unified) earthquake catalog for different seismic regions, various regression relation procedures have been used in various studies to convert different magnitude types to a preferred magnitude scale [Das et al. 2011]. Body wave magnitude, $\mathrm{m}_{\mathrm{b}}$, is a world-wide scale determined by the maximum amplitude of the first few seconds (usually about one second) of short-period $\mathrm{P}$ waves on the vertical component seismogram. Surface wave magnitude, $\mathrm{M}_{\mathrm{s}}$, is a world-wide scale determined from the amplitude of surface waves (usually Rayleigh waves) with a period of about 20 seconds [e.g., Reiter 1990]. Among different magnitude scales, $\mathrm{m}_{\mathrm{b}}$ begins to saturate at about 6 and $M_{s}$ at about 8 [e.g., Lay and Wallace 1995]. Therefore, it is rare for $m_{b}$ to exceed 7 or for $M_{s}$ to exceed 8.5, even for extremely large events [Shearer 2009]. Clearly, the most appropriate magnitude scale to use in most aspects of seismic studies is moment magnitude, $\mathrm{M}_{\mathrm{w}}$ [Kanamori 1977], which is scaled with the earthquake size through the scalar seismic moment, $\mathrm{M}_{\mathrm{o}}$. It does not suffer from saturation, and has a sounder physical basis [Kasahara 1985]. Due to the advantages of the $\mathrm{M}_{\mathrm{w}}$ magnitude scale, it is preferred to compile earthquake catalogs with all magnitudes expressed in this unified scale $\left(\mathrm{M}_{\mathrm{w}}\right)$ for the purposes of seismic hazard assessment and other important seismological problems having engineering applications [Das et al. 2011]. Among magnitude scales, $\mathrm{M}_{\mathrm{s}}$ has the most overlapping with $\mathrm{M}_{\mathrm{w}}$ below the saturation level [Kanamori 1977, Hanks and Kanamori 1979]. Comparison of $M_{s}$ and $M_{w}$ by Bormann and Dewey [2012] shows $M_{s}$ agree on average rather well with $\mathrm{M}_{\mathrm{w}}$ for magnitudes between 6.5 and $8+$.

Eliminating foreshocks and aftershocks leads approximately to a Poisson, or random data set for a better estimation of return periods of randomly occurring events (main-shock events), which is an important goal of seismic hazard studies [Oncel and Alptekin 1999]. The Gardner and Knopoff [1974] technique is a common used window method for removing aftershocks when the earthquake catalog has variable quality station coverage in different regions and time periods as proposed by Savage and DePolo [1993].

The question of completeness is paramount; nothing of value can be estimated from a statistical analysis 
with significant amounts of the data missing [VereJones 1992]. This can be the chief reason for the expression of Huang et al. [1994], who pointed out that "the completeness and reliability of data are the bases of earthquake research". The magnitude of completeness $\left(M_{c}\right)$ of an earthquake catalog (also called threshold or cutoff magnitude), is defined as the lowest magnitude at which $100 \%$ of the events in a space-time volume are detected [Rydelek and Sacks 1989, Taylor et al. 1990, Wiemer and Wyss 2000]. Usually, the completeness analysis is performed for declustered data, where dependent events have been removed [Grünthal and Wahlström 2012]. The magnitude of completeness may also change with time and space in most of the catalogs [Das et al. 2012].

The present study provides a unified and a declustered catalog of earthquakes in Iran which covers the area bounded in $22^{\circ}-42^{\circ} \mathrm{N}$ and $42^{\circ}-66^{\circ} \mathrm{E}$, including the territory of Iran and adjacent regions; eastern Iraq and eastern Turkey in the west, the Caucasus and southern Turkmenistan in the north, western Afghanistan and western Pakistan in the east, and Gulf of Oman and Persian Gulf in the south. Empirical formulae are established to convert $m_{b}$ to $M_{s}, m_{b}$ to $M_{w}, M_{s}$ to $M_{w}$ ,$M_{N}$ to $M_{w}$ and $M_{L}$ to $M_{w}$ using Standard Regression (SR), Inversed Standard Regression (ISR), Orthogonal Regression (OR) and General orthogonal regression (GOR). We applied conjugated windows comprised of two time and distance windows proposed by Gardner and Knopoff [1974], Uhrhammer [1986] and the cluster method proposed by Reasenberg [1985] to eliminate aftershocks from the unified earthquake catalog of the Iranian Plateau. Completeness threshold for different magnitude classes is estimated for declustered and unified catalog of earthquakes in major seismotectonic provinces of Iran and neighboring regions using the Entire-Magnitude-Range (EMR) method [Woessner and Wiemer 2005].

\section{Seismotectonic units}

The Iranian Plateau is bounded on the north by the Turan platform and on the south, by the Zagros collision zone and Makran subduction zone with the Arabian plate; it is a collage of different fragments of Gondwana land that accreted to the margins of Eurasia during several collisional orogenies [Berberian 1981, Berberian and Yeats 1999]. The Iranian Plateau is one of the most earthquake prone regions in the world. Many devastating earthquakes have occurred during the long history of this region [e.g., Ambraseys and Melville 1982, Berberian and Yeats 1999]. Frequency of moderate and large magnitude earthquake occurrences is different in various regions of the Iranian Plateau.
The seismicity of Iran suggests that much of the deformation is concentrated in the Zagros, Alborz and Kopeh Dagh mountains, and east Iran. Ye et al. [1993, 1995] defined seismotectonic province to be an area that, under the present-day geodynamic regimes, has a comparable tectonic setting and unified seismicity pattern. Based on all available geological, geophysical, tectonic and earthquake data, Mirzaei et al. [1998] subdivided the Iranian Plateau into five major seismotectonic provinces: (1) continental-continental collision zone of Zagros in southwest Iran, (2) highly seismic regions of Alborz-Azarbayejan covering north and northwest of Iran, which constitute a part of northern limit of Alpine-Himalayan orogenic belt, (3) Intraplate environment of Central-East Iran, (4) continental collision zone of Kopeh Dagh in northeast, (5) oceanic-continental subduction zone of Makran in southeast (Figure 1). In this study the above major seismotectonic provinces are entitled as ZG, AA, CE, KD and MK, respectively. This is a well-defined regionalization for seismotectonic provinces of Iran and many researchers have used this zonation in their works; for example, Ashtari [2007], Yazdani and Kowsari [2011], Tahernia et al. [2012], Zafarani and Soghart [2012], Karimiparidari et al. [2013], Abdi et al. [2013], and Zare et al. [2014]. It is clear that a further more and more detailed subdivision of the seismic areas will result an improvement in the reliability of time series of seismic events with a consequent increasing of both the precision in the determination of the parameters and the space resolution [Cosentino et al. 1977]. To further reflect the regional differences within each province, seismotectonic provinces can be subdivided into several subprovinces [e.g., Tahernia et al. 2011]. Due to the variability of local tectonic setting, seismicity level and the magnitude of maximum earthquake varies from place to place in a seismotectonic province; therefore, potential seismic sources with different magnitudes of maximum earthquake and different activity rates should be delineated within each province to represent a region with uniform seismic potential (see Mirzaei et al. [1999] for more information on potential seismic sources in Iran). Information regarding active tectonics of Iran is growing [e.g., Byrne et al. 1992, Berberian 1995, Bonini et al. 2003, Vernant et al. 2004, Walker and Jackson 2004, Berberian 2005, Masson et al. 2005, Hollingsworth et al. 2006, Jackson et al. 2006, Berberian and Walker 2010, Djamour et al. 2010, Allen et al. 2011, Smith et al. 2013, Walker et al. 2013, Berberian 2014, Walpersdorf et al. 2014], which can be used to define subprovinces and potential seismic sources more reliable. Recently, Mousavi-Bafrouei et al. [2014], re-evaluated the work of Mirzaei et al. [1999] and demarcated 238 potential seismic sources 


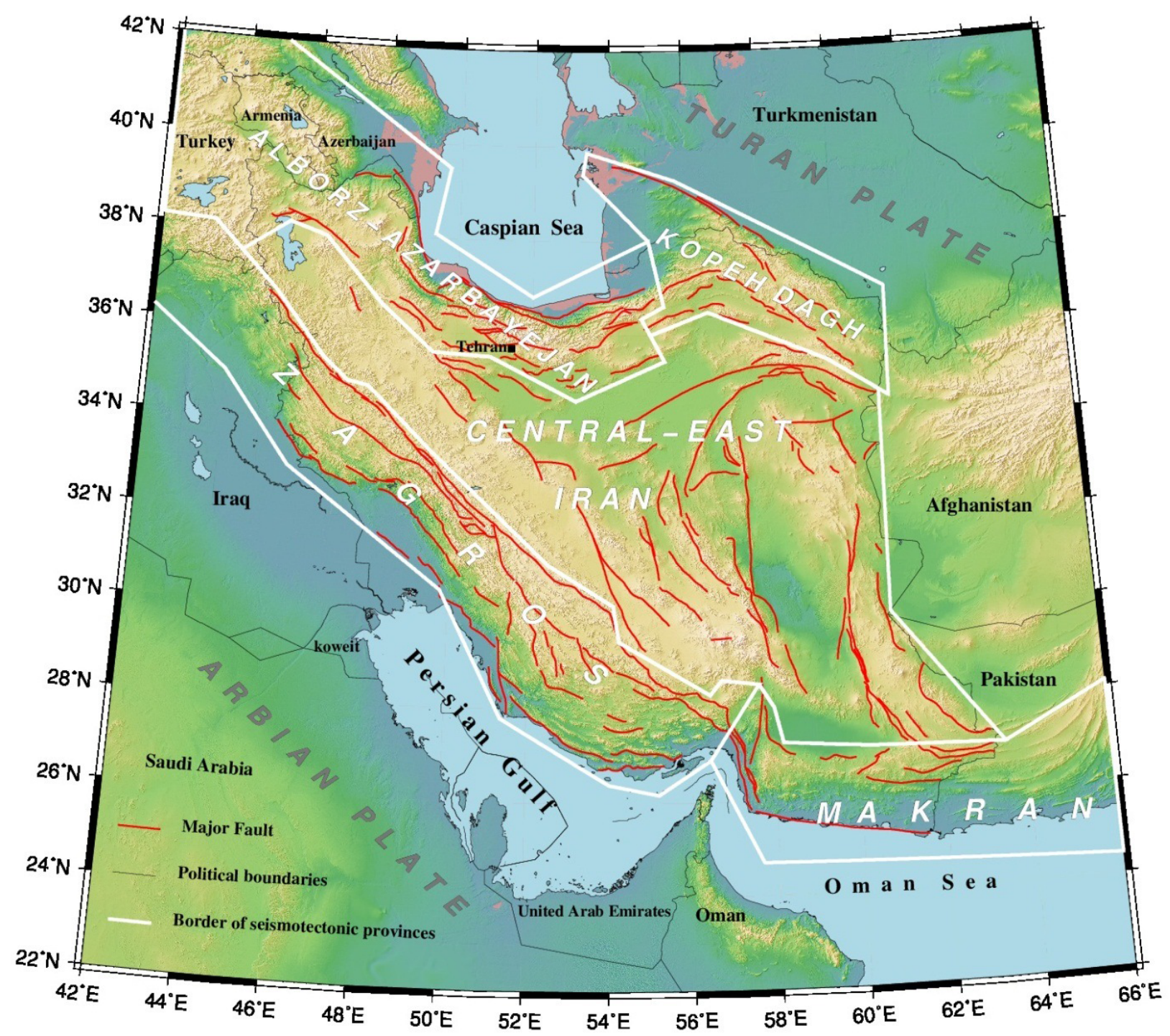

Figure 1. Major sismotectonic provinces of Iran developed by Mirzaei et al. [1998]. The Red lines depict the major active faults developed by Hessami et al. [2003].

within the five major seismotectonic provinces to generate a new seismic hazard zoning map of Iran.

\section{Catalog compilation}

Although the information concerning historical (pre-1900) seismicity of Iran is collected in variety of articles, such as Wilson [1930], Ambraseys [1968, 1974a], Berberian [1977], Seyed-Nabavi [1978], and Poirier and Taher [1980], more reliable information was found in Ambraseys and Melville [1982], which is based on critical evaluation of documentary materials and also direct observation in the field. The Ms magnitude is estimated for these events based on the macroseismic information, i.e. maximum intensity and radius of perceptibility, calibrated against macroseismic information of similar instrumental earthquakes. Epicenter coordinates of earthquakes are also adopted from Ambraseys and Melville [1982]. Earthquake catalogs by Mirzaei et al. [2002], entitled Basic Parameters of Earthquakes in Iran (BPEI) and Berberian [1994] were used as comple- mentary data sources for historical earthquakes, respectively. A total number of 448 historical earthquakes from 3rd millennium B.C. to 1899 exist in the data base from which 258 events from 4th century B.C. to 1899 incorporated in the unified catalog.

For early instrumental time-period (pre-WWSSN), it is generally accepted that, the macroseismic epicenters are more accurate than instrumental ones [e.g., Karnik 1969, Ambraseys and Melville 1982]. Careful field studies have shown that this is a fact regarding earthquakes in Iran. More discussions and details of field investigations can be found in Ambraseys and Moinfar [1973, 1974a, 1974b, 1975], Ambraseys [1974b, 1976, 1978, 1988], Ambraseys et al. [1973], Tchalenko and Braud [1974], Moinfar [1976] and Ambraseys and Melville [1982], among others. The presented catalog includes a total number of 752 earthquakes mainly based on macroseismic information, extracted from BPEI.

The modern instrumental earthquakes (after WWSSN) until 2000 are mainly based on BPEI; later 
earthquakes are compiled in this study, so that International Seismological Center (ISC) is the original reference; otherwise, we referred to National Earthquake Information Center/United States Geological Survey (NEIC).

A main priority system established to select the magnitude value to be preferred when an event is reported in several databases with different magnitude scales. The magnitude scales $m_{b}, M_{s}, M_{w}, M_{N}$ and $M_{L}$ reported by different agencies are compiled in our catalog. The main references for $\mathrm{m}_{\mathrm{b}}$ and $\mathrm{M}_{\mathrm{s}}$ are ISC and NEIC. The main references for $\mathrm{M}_{\mathrm{w}}$ are some miscellaneous studies; Ambraseys [2001], Baker et al. [1993], Berberian [2005], Jakson and McKenzie [1984] and Pristley et al. [1994]. Otherwise, the reference is Global Centroid-Moment-Tensor (GCMT), the first and the last published by the group Dziewonski et al. [1981] and Ekström et al. [2012], otherwise the reference is Swiss Seismological Service at the ETH Zurich (ETHZ) [Braunmiller et al. 2002]. The main reference for $\mathrm{M}_{\mathrm{N}}$, is the Iranian Seismological Center (IRSC) and for $\mathrm{M}_{\mathrm{L}}$ is the International Institute of Earthquake Engineering and Seismology (IIEES).

We promoted the pre-existing revised catalogs to optimize the location of events; EHB is a revised version of the ISC bulletin based on the algorithm of Engdahl et al. [1998], significantly improved routine hypocenter determinations made by the ISS (International Seismological Summary), ISC and PDE (Preliminary Determination of Epicenters from NEIC). It contains improved hypocenters for a number of 2591 events from $1960 / 04 / 02$ to $2008 / 12 / 31$ in the Iranian Plateau. The revised Iranian Seismological Center (IRSC) data base is used from 2006/03/01 to 2012/12/31 including 1417 local events.

The preferences of using different sources to compile earthquakes are sketched in Figure 2.

According to Utsu [2002], Scordilis [2006] and Gasperini et al. [2012] some attention should be taken into account when merging data from different seismological agencies. Scordilis [2006] resulted that throughout a wide range $\left(2.6 \leq \mathrm{M}_{\mathrm{S}, \text { ISC }} \leq 8.3\right), \mathrm{M}_{\mathrm{S}}$ estimated by ISC and by NEIC are practically identical irrespective of focal depth, allowing their consideration as a unified data set. Also, Utsu [2002] and Das et al. [2011] compared $M_{s}$ by ISC and by NEIC and found they can be taken as equivalent. In this study, $\mathrm{M}_{\mathrm{s}}$ estimated by ISC and by NEIC are taken as similar. The slight bias between $m_{b}$ estimated by ISC and by NEIC has been observed by some researchers [e.g., Utsu 2002]. According to Scordilis [2006], they are practically equivalent and the variation of $m_{b, I S C}$ versus $m_{b, N E I C}$ is as follows: $\mathrm{m}_{\mathrm{b}, \mathrm{ISC}}=1.02( \pm 0.003) \mathrm{m}_{\mathrm{b}, \mathrm{NEIC}} 0.18( \pm 0.01)$ for $0.25 \leq \mathrm{m}_{\mathrm{b}, \mathrm{NEIC}} \leq 7.3$

Gasperini et al. [2012] compared $\mathrm{M}_{\mathrm{w}}$ estimates for the European-Mediterranean and Italian regions and concluded that, no scaling correction is needed and an offset correction ranging between -0.05 to -0.08 units has to be applied to ETHZ to make it compatible with GCMT. Since large parts of Iran are located in their study area, we applied -0.05 unites to $M_{w}$ reported by ETHZ to make it compatible with $M_{w}$ reported by GCMT.

To compare the uncertainty of $\mathrm{M}_{\mathrm{w}}$ reported by GCMT and ETHZ, we calculated the standard deviation for each one separately; 0.384 for GCMT and 0.404 for ETHZ data. According to Gasperini et al. [2012] the approximate equality of the standard deviations for GCMT and ETHZ catalogs suggests that magnitude uncertainties for both catalogs are approximately equal. We also compared $\mathrm{M}_{\mathrm{w}}$ reported by GCMT and ETHZ with a third magnitude, $\mathrm{m}_{\mathrm{b}}$ reported by ISC and NEIC, considering the variation of $\mathrm{m}_{\mathrm{b}, \mathrm{ISC}}$ versus $\mathrm{m}_{\mathrm{b}, \mathrm{NEIC}}$ (relation 1). The values of $\sigma_{\Delta \mathrm{m}}$ for $\mathrm{M}_{\mathrm{w}, \mathrm{GCMT}}-\mathrm{m}_{\mathrm{b}}$ and $\mathrm{M}_{\mathrm{w}, \mathrm{ETH}}-\mathrm{m}_{\mathrm{b}}$ are determined to be 0.233 and 0.241 , respectively. Ac-

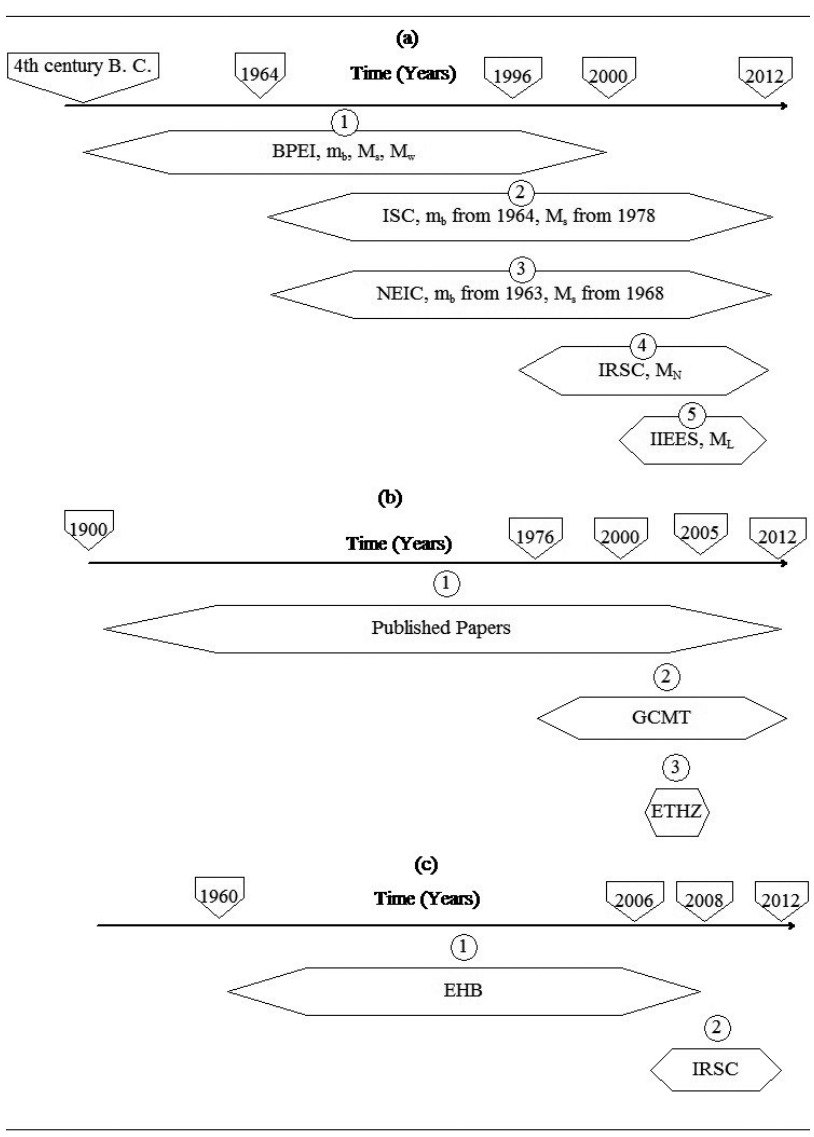

Figure 2. Priority order of data selection from various agencies. (a) Preparing the master catalog, (b) adjoining moment magnitude, (c) optimizing the location of events. See text for description of abbreviations. 
cording to Kagan [2003] approximate equality of $\sigma_{\Delta \mathrm{m}}$ values suggests that magnitude uncertainties for both catalogs are equal. The correction ( -0.05 to ETHZ) proposed by Gasperini et al. [2012], is also applied and the standard deviation $\sigma_{\Delta \mathrm{m}}$ for magnitude difference between $\mathrm{M}_{\mathrm{w}}$ reported by GCMT and ETHZ, is estimated 0.139 . The variance for the magnitude difference is the result of the standard deviations in catalogs [e.g., Kagan 2003]:

$$
\sigma_{\Delta \mathrm{m}}^{2}=\sigma_{\mathrm{m} 1}^{2}+\sigma_{\mathrm{m} 2}^{2}
$$

where $\sigma_{\mathrm{m} 1}$ and $\sigma_{\mathrm{m} 2}$ are the standard deviations for both catalogs. Since the magnitude uncertainties for $M_{w}$ from ETHZ and GCMT are approximately equal, we can estimate the uncertainties for $M_{w}$ as [Kagan 2003]:

$$
\sigma_{\mathrm{M}_{\mathrm{w}}}=\frac{\sigma_{\Delta \mathrm{m}}}{\sqrt{2}}
$$

this gives $\sigma_{\mathrm{M}_{\mathrm{w}}}=0.098 \approx 0.1$.

\section{Magnitude conversion relations}

Until recently, regression analyses for conversions between different types of magnitude were using the Standard least square Regression (SR) method or the simple Orthogonal Regression (OR) method, which assume equal uncertainties for the two variables. The latter is obtained using minimization of the squares of the orthogonal distances to the best-fit line, whereas SR is derived by minimizing the squares of the vertical offsets and Inverted Standard least-squares Regression (ISR) is derived by minimizing the squares of the horizontal offsets. In case both the magnitudes have measurement errors, it is appropriate to use OR procedure which takes into account the errors on both the magnitudes [e.g., Stromeyer et al. 2004, Castellaro et al. 2006, Castellaro and Bormann 2007]. Castellaro et al. [2006] suggested the use of the General Orthogonal Regression (GOR) method [Fuller 1987] that requires only the ratio $\eta$ between the variances of the two variables is known [Gasperini et al. 2012]. Castellaro and Bormann [2007] analyzed orthogonal regression in its general formulation GOR and compared its performance with SR and ISR. They concluded that when square root of the error variance ratio is less than 0.7 and greater than 1.8, either ISR or SR relation is better than OR (GOR relation with $\eta=1$ ).

Lolli and Gasperini [2012] compared three methods of general orthogonal linear regression for magnitude conversion: the Chi Square Regression (CSQ) [Stromeyer et al. 2004], the GOR [Fuller 1987, Castellaro et al. 2006], and the Weighted Total Least Squares (WTLS) [Krystek and Anton 2007, Bethmann et al. 2011]. They found that under the common assumption that only the variances ratio

$$
\eta=\frac{\sigma_{y}^{2}}{\sigma_{x}^{2}}
$$

is known, three above mentioned methods are substantially equivalent. Moreover, Wason et al. [2012] asserted that as the derivation of GOR is based on the orthogonal projection of observed magnitude data pairs on the GOR line, the calculation of estimates of a preferred magnitude type using these GOR relations in their existing form is liable to introduce errors. They proposed a method that is detailed in Wason et al. [2012] and Das et al. [2012] and used in Das et al. [2013]. Gasperini and Lolli [2014a, 2014b] published comments on the method introduced by Das et al. [2012] and Wason et al. [2012] and pointed out that such procedure is wrong for a number of theoretical and empirical reasons.

$$
\text { 4.1. } m_{b}-M_{w}
$$

The conversion relations between $\mathrm{m}_{\mathrm{b}}$ and $\mathrm{M}_{\mathrm{w}}$ are estimated for events where $m_{b} \leq 6.2$ to avoid the saturation effect. After applying the corrections according to relation 1, the standard deviation $\sigma_{\Delta \mathrm{m}}$ of magnitude difference between $M_{w}$ and $m_{b}$ is estimated to be 0.235 . Using relation 2 and the estimated uncertainty of $\mathrm{M}_{\mathrm{w}}$, the uncertainty of $\mathrm{m}_{\mathrm{b}}$ is estimated to be 0.213 . The error variances ratio

$$
\eta=\frac{\sigma_{\mathrm{M}_{\mathrm{w}}}^{2}}{\sigma_{\mathrm{m}_{\mathrm{b}}}^{2}}
$$

is estimated to be 0.22 . Because the estimated square root of $\eta$ is 0.47 , according to Castellaro and Bormann [2007], the ISR performs better, as compared with the $\mathrm{SR}$ and the OR relations. However, we preferred to estimate the $\mathrm{m}_{\mathrm{b}}-\mathrm{M}_{\mathrm{w}}$ relations for each seismotectonic province, using the GOR method with $\eta=0.22$.

Gasperini et al. [2012] compared two different datasets and relevant conversion relations by two different statistical indicators: the mean magnitude difference (d) and the slope coefficient from the GOR method (a) using the student's t-test. Similarly, we compared five datasets for the five major seismotectonic provinces in Iran and relevant conversion relations by the two statistical indicators- $\mathrm{d}$ and a using one-way analysis of variance (ANOVA) and a post-hoc analysis, the Tukey Honest Significant Difference (HSD) test [NIST/SEMATECH 2012]. The magnitude difference (d) for each region is inclusive $\mathrm{N}$ data that is participated in the ANOVA and the Tukey test. Following, in Tables 1 to 5 , only the mean and $95 \%$ confidence interval of these data are presented. The slope coefficient (a) for each region is estimated in terms of the 
mean and the standard deviation of the mean and $95 \%$ confidence interval using the GOR method. For doing the ANOVA and the Tukey test, we generated N normal distributed random data for each region based on mean and standard deviation of the mean which is estimated for the slope coefficient. If the statistical indicators for some regions are equal, their data sets will be merged. Otherwise, the data sets will be considered separately. We estimated the significance levels (s.l.) at which we can reject the two $\mathrm{H}_{0}$ hypotheses-the equality of slope coefficients and the equality of mean differences for the five regions using ANOVA. As a post-hoc analysis, the Tukey test is used to evaluate the equality of the slope coefficients and that of the mean differences $\mathrm{H}_{0}$ hypotheses for each pair of the data set. According to common statistical practice, we can confidently reject the $\mathrm{H}_{0}$ hypothesis if the s.l. is lower than 0.01 , and tentatively reject the hypothesis if the s.l. is larger than 0.01 but lower than 0.05 [Gasperini et al. 2012].

The s.l. for rejecting the $\mathrm{H}_{0}$ hypotheses-the equality of slope coefficients and the equality of mean differences for the five regions is estimated to be 0.008 and $<0.001$, respectively. Based on the ANOVA, we can assert that the differences between slope coefficients and those between mean differences for the five regions are significant. Information about the five data sets and the results of Tukey test are shown in Table 1. The data sets, which are significantly different from others at the 0.05 level, are bolded in Table 1. As shown in Table 1, the Tukey test indicates that the slope coefficients for ZG and CE are slightly different $(\mathrm{s} .1 .=0.043)$, but that for $Z G$ is not different from the other regions. In addition, the result of the Tukey test regarding the mean differences of the data sets indicates that the mean difference for ZG is significantly different from those for $\mathrm{CE}$ and AA (s.l. of both are $<0.001$ ). On the other hand, the slope coefficients and the mean difference for AA, $\mathrm{CE}, \mathrm{KD}$, and $\mathrm{MK}$ are not significantly different (Table 1). Hence, we kept the data from $Z G$ separate and merged the data sets from the four other regions. Eventually, we estimated $m_{b}-M_{w}$ relations for three data sets-the first taken from ZG (relation 4), the second taken from the four other regions (relation 5 ), and the third taken from all of them (relation 6) using the GOR method.

$\mathrm{M}_{\mathrm{w}}=1.207( \pm 0.039) \mathrm{m}_{\mathrm{b}}-0.933( \pm 0.193)$,

$\mathrm{R}^{2}=0.73, \sigma=0.24, \mathrm{n}=353,3.9 \leq \mathrm{m}_{\mathrm{b}} \leq 6.1, \eta=0.22$, for ZG

$\mathrm{M}_{\mathrm{w}}=1.332( \pm 0.048) \mathrm{m}_{\mathrm{b}}-1.474( \pm 0.246)$,

$\mathrm{R}^{2}=0.8, \sigma=0.25, \mathrm{n}=229,4 \leq \mathrm{m}_{\mathrm{b}} \leq 6.2, \eta=0.22$, for $\mathrm{AA}, \mathrm{CE}, \mathrm{KD}$ and $\mathrm{MK}$

$\mathrm{M}_{\mathrm{w}}=1.298( \pm 0.03) \mathrm{m}_{\mathrm{b}}-1.349( \pm 0.152)$,

$\mathrm{R}^{2}=0.76, \sigma=0.26, \mathrm{n}=582,3.9 \leq \mathrm{m}_{\mathrm{b}} \leq 6.2, \eta=0.22$, for all provinces.

\begin{tabular}{|c|c|c|c|c|c|}
\hline Data set & $\mathrm{AA}$ & CE & $\mathrm{KD}$ & MK & ZG \\
\hline No. of data & 102 & 87 & 21 & 19 & 353 \\
\hline Magnitude interval & $4.2 \leq \mathrm{m}_{\mathrm{b}} \leq 6.2$ & $4.4 \leq \mathrm{m}_{\mathrm{b}} \leq 6.2$ & $4.4 \leq \mathrm{m}_{\mathrm{b}} \leq 5.8$ & $4.8 \leq \mathrm{m}_{\mathrm{b}} \leq 5.9$ & $4.1 \leq \mathrm{m}_{\mathrm{b}} \leq 6.2$ \\
\hline Intercept & $-1.261 \pm 0.552$ & $-1.764 \pm 0.748$ & $-2.618 \pm 2.388$ & $-1.451 \pm 1.653$ & $-0.933 \pm 0.338$ \\
\hline Slope a & $1.291 \pm 0.109$ & $1.389 \pm 0.144$ & $1.564 \pm 0.473$ & $1.309 \pm 0.306$ & $1.207 \pm 0.068$ \\
\hline Mean difference d & $0.205 \pm 0.046$ & $0.276 \pm 0.056$ & $0.226 \pm 0.111$ & $0.215 \pm 0.082$ & $0.089 \pm 0.023$ \\
\hline \multirow{4}{*}{$\begin{array}{l}\text { s.l. for rejecting the } \\
\text { equality of slope a }\end{array}$} & $\left(\mathrm{a}_{\mathrm{AA}}=\mathrm{a}_{\mathrm{CE}}\right) 0.860$ & $\left(\mathrm{a}_{\mathrm{CE}}=\mathrm{a}_{\mathrm{KD}}\right) 0.869$ & $\left(\mathrm{a}_{\mathrm{KD}}=\mathrm{a}_{\mathrm{MK}}\right) 0.740$ & $\left(\mathrm{a}_{\mathrm{MK}}=\mathrm{a}_{\mathrm{ZG}}\right) 0.936$ & $\left(a_{Z G}=a_{A A}\right) 0.443$ \\
\hline & $\left(\mathrm{a}_{\mathrm{AA}}=\mathrm{a}_{\mathrm{KD}}\right) 0.507$ & $\left(\mathrm{a}_{\mathrm{CE}}=\mathrm{a}_{\mathrm{MK}}\right) 0.976$ & $\left(\mathrm{a}_{\mathrm{KD}}=\mathrm{a}_{\mathrm{ZG}}\right) 0.084$ & $\left(\mathrm{a}_{\mathrm{MK}}=\mathrm{a}_{\mathrm{AA}}\right) 1.000$ & $\left(a_{\mathrm{ZG}}=\mathrm{a}_{\mathrm{CE}}\right) \mathbf{0 . 0 4 3}$ \\
\hline & $\left(\mathrm{a}_{\mathrm{AA}}=\mathrm{a}_{\mathrm{MK}}\right) 1.000$ & $\left(a_{\mathrm{CE}}=a_{\mathrm{ZG}}\right) 0.043$ & $\left(\mathrm{a}_{\mathrm{KD}}=\mathrm{a}_{\mathrm{AA}}\right) 0.507$ & $\left(\mathrm{a}_{\mathrm{MK}}=\mathrm{a}_{\mathrm{CE}}\right) 0.976$ & $\left(\mathrm{a}_{\mathrm{ZG}}=\mathrm{a}_{\mathrm{KD}}\right) 0.084$ \\
\hline & $\left(\mathrm{a}_{\mathrm{AA}}=\mathrm{a}_{\mathrm{ZG}}\right) 0.443$ & $\left(\mathrm{a}_{\mathrm{CE}}=\mathrm{a}_{\mathrm{AA}}\right) 0.860$ & $\left(\mathrm{a}_{\mathrm{KD}}=\mathrm{a}_{\mathrm{CE}}\right) 0.869$ & $\left(\mathrm{a}_{\mathrm{MK}}=\mathrm{a}_{\mathrm{KD}}\right) 0.740$ & $\left(\mathrm{a}_{\mathrm{ZG}}=\mathrm{a}_{\mathrm{MK}}\right) 0.936$ \\
\hline \multirow{4}{*}{$\begin{array}{l}\text { s.l. for rejecting the } \\
\text { equality of mean } \\
\text { difference d }\end{array}$} & $\left(\mathrm{d}_{\mathrm{AA}}=\mathrm{d}_{\mathrm{CE}}\right) 0.207$ & $\left(\mathrm{~d}_{\mathrm{CE}}=\mathrm{d}_{\mathrm{KD}}\right) 0.893$ & $\left(\mathrm{~d}_{\mathrm{KD}}=\mathrm{d}_{\mathrm{MK}}\right) 1.000$ & $\left(\mathrm{~d}_{\mathrm{MK}}=\mathrm{d}_{\mathrm{ZG}}\right) 0.142$ & $\left(\mathrm{~d}_{\mathrm{ZG}}=\mathrm{d}_{\mathrm{AA}}\right) \mathbf{0 . 0 0 0}$ \\
\hline & $\left(\mathrm{d}_{\mathrm{AA}}=\mathrm{d}_{\mathrm{KD}}\right) 0.996$ & $\left(\mathrm{~d}_{\mathrm{CE}}=\mathrm{d}_{\mathrm{MK}}\right) 0.844$ & $\left(\mathrm{~d}_{\mathrm{KD}}=\mathrm{d}_{\mathrm{ZG}}\right) 0.059$ & $\left(\mathrm{~d}_{\mathrm{MK}}=\mathrm{d}_{\mathrm{AA}}\right) 1.000$ & $\left(\mathrm{~d}_{\mathrm{ZG}}=\mathrm{d}_{\mathrm{CE}}\right) \mathbf{0 . 0 0 0}$ \\
\hline & $\left(\mathrm{d}_{\mathrm{AA}}=\mathrm{d}_{\mathrm{MK}}\right) 1.000$ & $\left(\mathrm{~d}_{\mathrm{CE}}=\mathrm{d}_{\mathrm{ZG}}\right) \mathbf{0 . 0 0 0}$ & $\left(\mathrm{d}_{\mathrm{KD}}=\mathrm{d}_{\mathrm{AA}}\right) 0.996$ & $\left(\mathrm{~d}_{\mathrm{MK}}=\mathrm{d}_{\mathrm{CE}}\right) 0.844$ & $\left(\mathrm{~d}_{\mathrm{ZG}}=\mathrm{d}_{\mathrm{KD}}\right) 0.59$ \\
\hline & $\left(d_{A A}=d_{Z G}\right) 0.000$ & $\left(\mathrm{~d}_{\mathrm{CE}}=\mathrm{d}_{\mathrm{AA}}\right) 0.207$ & $\left(\mathrm{~d}_{\mathrm{KD}}=\mathrm{d}_{\mathrm{CE}}\right) 0.893$ & $\left(\mathrm{~d}_{\mathrm{MK}}=\mathrm{d}_{\mathrm{KD}}\right) 1.000$ & $\left(\mathrm{~d}_{\mathrm{ZG}}=\mathrm{d}_{\mathrm{MK}}\right) 0.142$ \\
\hline
\end{tabular}

Table 1. GOR coefficients and Mean differences for the $m_{b}-M_{w}$ data sets. Significance levels (s.l.) indicate the probabilities of rejecting the corresponding $\mathrm{H}_{0}$ hypotheses (within parentheses) when they are true (in boldface when $<0.05$ ). Values after \pm indicate $95 \%$ confidence interval. AA: Alborz-Azarbayejan, CE: Central-East Iran, KD: Kopeh Dagh, MK: Makran and ZG: Zagros. 


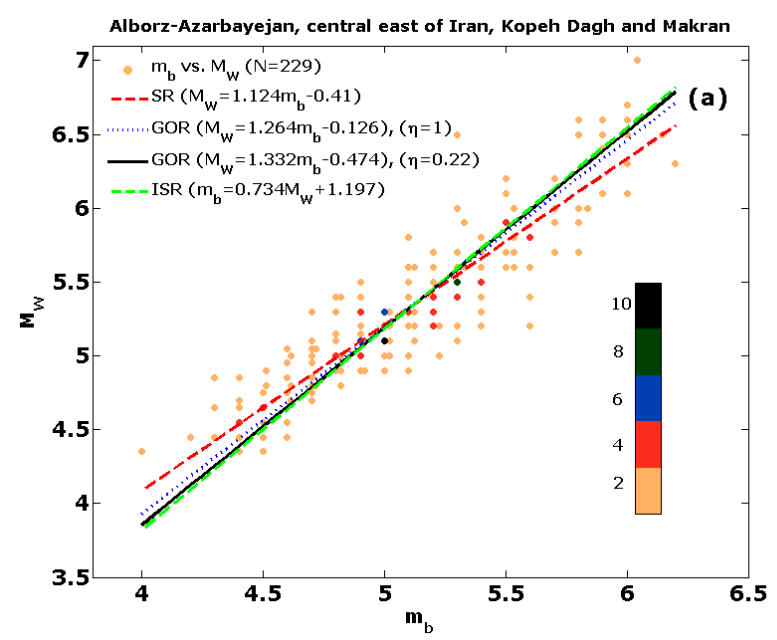

Figure 3 (clockwise from above left). $\mathrm{m}_{\mathrm{b}}-\mathrm{M}_{\mathrm{w}}$ conversion relations for major seismotectonic provinces in Iran. SR: standard regression, ISR: inversed standard regression and GOR: general orthogonal regression.

In relations 4 to 6 and in the next relations to 16 , values that come within parentheses after \pm , are $68 \%$ confidence interval of relevant coefficients.

For comparison, conversion relations from SR, ISR, OR, and GOR are shown in Figure 3. As shown, the line obtained from the GOR with the estimated is located between the OR line and the ISR line, albeit closer to the ISR line. This is expected because the error of the horizontal component $\sigma_{\mathrm{m}_{\mathrm{b}}}$ is greater than that of the vertical component $\sigma_{\mathrm{M}_{\mathrm{w}}}$.

\section{2. $M_{s}-M_{w}$}

There are 519 earthquakes in the catalog for which $\mathrm{M}_{\mathrm{s}}$ and $\mathrm{M}_{\mathrm{w}}$ are both reported. As Figure 4 reveals, a bilinear regression best fit the data. $\mathrm{M}_{\mathrm{s}}-\mathrm{M}_{\mathrm{w}}$ pairs can be divided into two groups; 37 events with $M_{s}>6.1$ and 482 events with $M_{s} \leq 6.1$. The standard deviation of magnitude difference $\sigma_{\Delta \mathrm{m}}$ between $\mathrm{M}_{\mathrm{w}}$ and $\mathrm{M}_{\mathrm{s}}$ for $\mathrm{M}_{\mathrm{s}} \leq 6.1$, for $M_{s}>6.1$ and for all range of $M_{s}$ are estimated to be $0.306,0.184$ and 0.337 , respectively. Using relation 2 and the estimated uncertainty of $\mathrm{M}_{\mathrm{w}}$, the uncertainty of $\mathrm{M}_{\mathrm{s}}$ for $M_{s} \leq 6.1, M_{s}>6.1$ and for all range of $M_{s}$ are estimated to be $0.289,0.185$ and 0.322 , respectively. The error variances ratio

$$
\eta=\frac{\sigma_{\mathrm{M}_{\mathrm{w}}}^{2}}{\sigma_{\mathrm{M}_{\mathrm{s}}}^{2}}
$$

for $M_{s} \leq 6.1$ and for $M_{s}>6.1$ are found to be 0.12 and 0.42 respectively. Because the square root of $\eta$ for $M_{s} \leq 6.1$ and for $M_{s}>6.1$ are 0.346 and 0.646 respectively, according to Castellaro and Bormann [2007], the ISR performs better, as compared with the SR and the OR relations. However, we preferred to estimate the GOR relations for conversion of $M_{s}$ to $M_{w}$ with the estimated $\eta$.

Due to lack of the sufficient data for $M_{s}>6.1$ in each province, the data are divided into two parts and
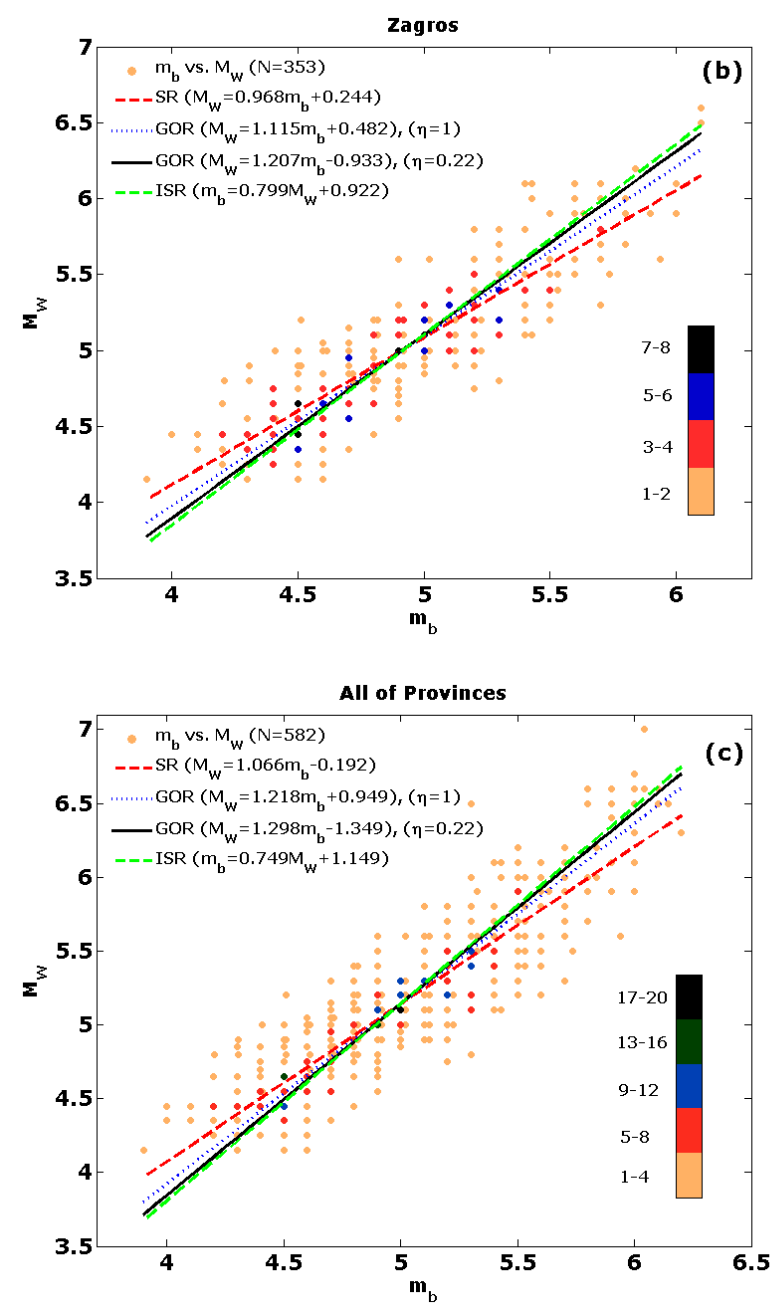

the relations are established using the GOR method with $\eta=0.42$. The first part includes 17 events of AA, ZG and $\mathrm{KD}$. The second part contains 20 events of $\mathrm{CE}$ and MK (Table 4). The s.l. for rejecting the $\mathrm{H}_{0}$ hypotheses- $\mathrm{a}_{\mathrm{AA}, \mathrm{ZG}, \mathrm{KD}}=\mathrm{a}_{\mathrm{CE}, \mathrm{MK}}$ and $\mathrm{d}_{\mathrm{AA}, \mathrm{ZG}, \mathrm{KD}}=\mathrm{d}_{\mathrm{CE}, \mathrm{MK}}$, are estimated to be 0.964 and 0.196 , respectively. Based on the ANOVA, we can assert that the difference between slope coefficients and that between mean differences of the two data sets are not significant. Hence, we esti-

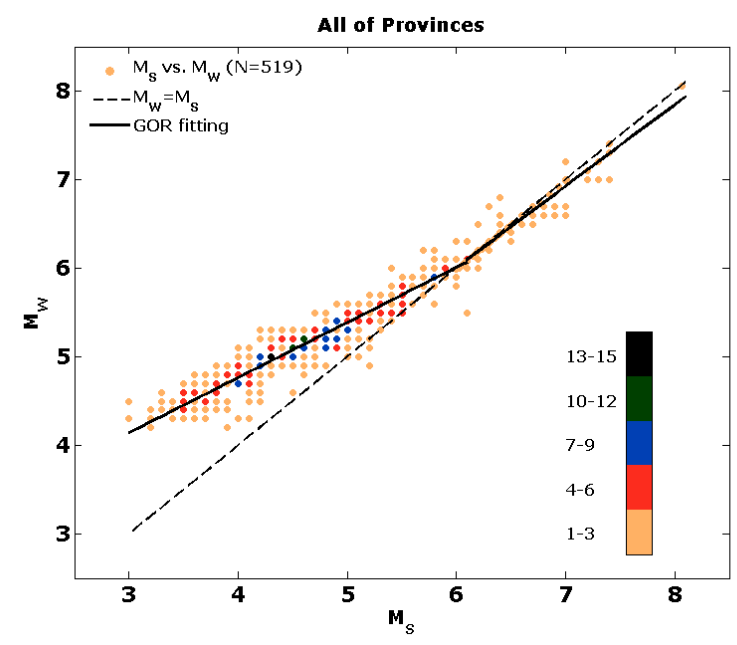

Figure 4. Bilinear regression is the best fit for $\mathrm{M}_{\mathrm{s}}-\mathrm{M}_{\mathrm{w}}$ data. 


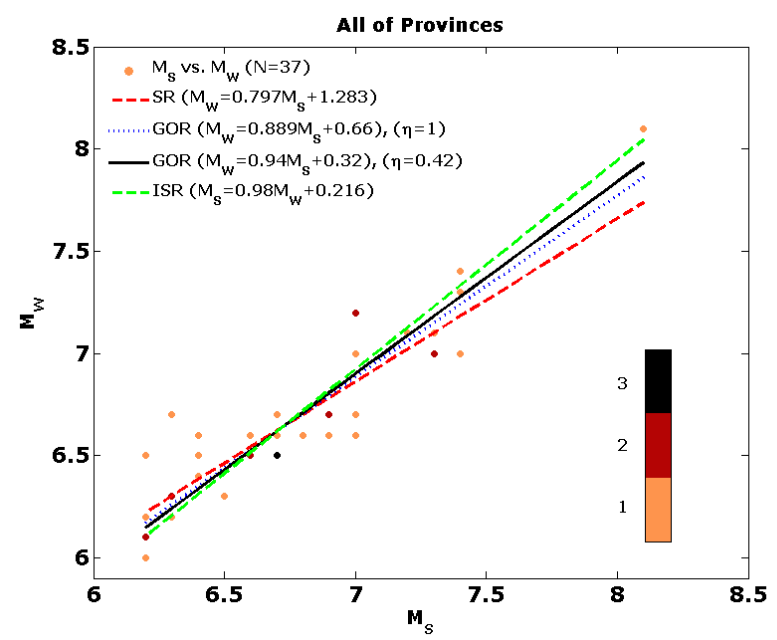

Figure 5. $\mathrm{M}_{\mathrm{S}}-\mathrm{M}_{\mathrm{w}}$ conversion relations for the Iranian Plateau $\left(M_{s}>6.1\right)$. Abbreviations as Figure 3.

mated conversion relation $\mathrm{M}_{\mathrm{s}}-\mathrm{M}_{\mathrm{w}}$ using the GOR method for the merged data sets.

$\mathrm{M}_{\mathrm{w}}=0.94( \pm 0.094) \mathrm{M}_{\mathrm{s}}+0.32( \pm 0.637)$

$\mathrm{R}^{2}=0.76, \sigma=0.17, \mathrm{n}=37,6.2 \leq \mathrm{M}_{\mathrm{s}} \leq 8.1, \eta=0.42$, for all provinces.

For comparison, conversion relations of $\mathrm{M}_{\mathrm{s}}-\mathrm{M}_{\mathrm{w}}$ from SR, ISR, OR and GOR for $\mathrm{M}_{\mathrm{s}}>6.1$, are shown in Figure 5. As shown, the line obtained from the GOR method is located between the OR line and the ISR line.

Numbers of earthquakes with $M_{s} \leq 6.1$ are statistically sufficient to establish $M_{s}-M_{w}$ relation for each seismotectonic province individually. The $\mathrm{M}_{\mathrm{s}}-\mathrm{M}_{\mathrm{w}}$ rela- tion for each seismotectonic province for $M_{s} \leq 6.1$ are estimated by the GOR method with $\eta=0.12$ (Table 2). The s.l. for rejecting $\mathrm{H}_{0}$ hypotheses-equality of slope coefficients and equality of mean differences for the five regions, are estimated to be 0.005 and $<0.001$, respectively. Based on the ANOVA, we can assert that the differences between slope coefficients and those between mean differences of the data sets from the five regions are significant. The results of Tukey test, shown in Table 2, indicate that, the slope coefficients for AA and $\mathrm{CE}$ are different $(\mathrm{s} .1 .=0.011)$, but that for AA is not different from the other regions. In addition, the result of the Tukey test regarding the mean differences of the data sets indicate that, the mean difference for $\mathrm{AA}$ is significantly different from those from $\mathrm{CE}, \mathrm{KD}$ and $\mathrm{ZG}$ (s.l. of all are $<0.001$ ). On the other hand, the slope coefficients and the mean differences for $\mathrm{CE}, \mathrm{KD}, \mathrm{MK}$ and ZG aren't significantly different (Table 1). Hence, we kept the data from AA separate and merged the data sets from the four other regions. Eventually, we estimated $\mathrm{M}_{\mathrm{s}}-\mathrm{M}_{\mathrm{w}}$ relations for three data sets-the first taken from AA (relation 8), the second taken from four other regions (relation 9) and the third taken from all of them (relation 10), using the GOR method.

$\mathrm{M}_{\mathrm{w}}=0.763( \pm 0.044) \mathrm{M}_{\mathrm{s}}+1.593( \pm 0.209)$,

$\mathrm{R}^{2}=0.84, \sigma=0.18, \mathrm{n}=75,3.4 \leq \mathrm{M}_{\mathrm{s}} \leq 6.1, \eta=0.12$, for AA,

$\mathrm{M}_{\mathrm{w}}=0.679( \pm 0.017) \mathrm{M}_{\mathrm{s}}+2.004( \pm 0.075)$,

\begin{tabular}{|c|c|c|c|c|c|}
\hline Data set & $\mathrm{AA}$ & $\mathrm{CE}$ & $\mathrm{KD}$ & MK & $Z G$ \\
\hline No. of data & 75 & 72 & 20 & 18 & 297 \\
\hline Magnitude interval & $3.4 \leq M_{s} \leq 6.1$ & $4.4 \leq M_{s} \leq 6.1$ & $4.4 \leq M_{s} \leq 5.8$ & $4.8 \leq \mathrm{M}_{\mathrm{s}} \leq 5.9$ & $4.1 \leq M_{s} \leq 6.1$ \\
\hline Intercept & $1.59 \pm 0.314$ & $2.25 \pm 0.244$ & $2.259 \pm 0.569$ & $2.443 \pm 0.494$ & $1.926 \pm 0.134$ \\
\hline Slope & $0.763 \pm 0.066$ & $0.632 \pm 0.05$ & $0.607 \pm 0.114$ & $0.603 \pm 0.094$ & $0.668 \pm 0.03$ \\
\hline Mean difference & $0.306 \pm 0.064$ & $0.532 \pm 0.067$ & $0.646 \pm 0.131$ & $0.428 \pm 0.161$ & $0.576 \pm 0.033$ \\
\hline \multirow{4}{*}{$\begin{array}{l}\text { s.l. for rejecting the } \\
\text { equality of slope a }\end{array}$} & $\left(a_{\mathrm{AA}}=\mathrm{a}_{\mathrm{CE}}\right) 0.011$ & $\left(\mathrm{a}_{\mathrm{CE}}=\mathrm{a}_{\mathrm{KD}}\right) 0.998$ & $\left(\mathrm{a}_{\mathrm{KD}}=\mathrm{a}_{\mathrm{MK}}\right) 1.00$ & $\left(\mathrm{a}_{\mathrm{MK}}=\mathrm{a}_{\mathrm{ZG}}\right) 0.566$ & $\left(a_{\mathrm{ZG}}=\mathrm{a}_{\mathrm{AA}}\right) 0.212$ \\
\hline & $\left(\mathrm{a}_{\mathrm{AA}}=\mathrm{a}_{\mathrm{KD}}\right) 0.107$ & $\left(\mathrm{a}_{\mathrm{CE}}=\mathrm{a}_{\mathrm{MK}}\right) 0.9760 .995$ & $\left(\mathrm{a}_{\mathrm{KD}}=\mathrm{a}_{\mathrm{ZG}}\right) 0.583$ & $\left(\mathrm{a}_{\mathrm{MK}}=\mathrm{a}_{\mathrm{AA}}\right) 0.110$ & $\left(\mathrm{a}_{\mathrm{ZG}}=\mathrm{a}_{\mathrm{CE}}\right) 0.275$ \\
\hline & $\left(\mathrm{a}_{\mathrm{AA}}=\mathrm{a}_{\mathrm{MK}}\right) 0.110$ & $\left(\mathrm{a}_{\mathrm{CE}}=\mathrm{a}_{\mathrm{ZG}}\right) 0.275$ & $\left(\mathrm{a}_{\mathrm{KD}}=\mathrm{a}_{\mathrm{AA}}\right) 0.107$ & $\left(\mathrm{a}_{\mathrm{MK}}=\mathrm{a}_{\mathrm{CE}}\right) 0.995$ & $\left(\mathrm{a}_{\mathrm{ZG}}=\mathrm{a}_{\mathrm{KD}}\right) 0.583$ \\
\hline & $\left(\mathrm{a}_{\mathrm{AA}}=\mathrm{a}_{\mathrm{ZG}}\right) 0.212$ & $\left(\mathrm{a}_{\mathrm{CE}}=\mathrm{a}_{\mathrm{AA}}\right) 0.011$ & $\left(\mathrm{a}_{\mathrm{KD}}=\mathrm{a}_{\mathrm{CE}}\right) 0.998$ & $\left(\mathrm{a}_{\mathrm{MK}}=\mathrm{a}_{\mathrm{KD}}\right) 1.00$ & $\left(\mathrm{a}_{\mathrm{ZG}}=\mathrm{a}_{\mathrm{MK}}\right) 0.566$ \\
\hline \multirow{4}{*}{$\begin{array}{l}\text { s.l. for rejecting the } \\
\text { equality of mean } \\
\text { difference d }\end{array}$} & $\left(\mathrm{d}_{\mathrm{AA}}=\mathrm{d}_{\mathrm{CE}}\right) \mathbf{0 . 0 0 0}$ & $\left(\mathrm{d}_{\mathrm{CE}}=\mathrm{d}_{\mathrm{KD}}\right) 0.513$ & $\left(\mathrm{~d}_{\mathrm{KD}}=\mathrm{d}_{\mathrm{MK}}\right) 0.136$ & $\left(\mathrm{~d}_{\mathrm{MK}}=\mathrm{d}_{\mathrm{ZG}}\right) 0.218$ & $\left(\mathrm{~d}_{\mathrm{ZG}}=\mathrm{d}_{\mathrm{AA}}\right) \mathbf{0 . 0 0 0}$ \\
\hline & $\left(d_{A A}=d_{K D}\right) 0.000$ & $\left(\mathrm{~d}_{\mathrm{CE}}=\mathrm{d}_{\mathrm{MK}}\right) 0.651$ & $\left(\mathrm{~d}_{\mathrm{KD}}=\mathrm{d}_{\mathrm{ZG}}\right) 0.824$ & $\left(\mathrm{~d}_{\mathrm{MK}}=\mathrm{d}_{\mathrm{AA}}\right) 0.498$ & $\left(\mathrm{~d}_{\mathrm{ZG}}=\mathrm{d}_{\mathrm{CE}}\right) 0.774$ \\
\hline & $\left(\mathrm{d}_{\mathrm{AA}}=\mathrm{d}_{\mathrm{MK}}\right) 0.498$ & $\left(\mathrm{~d}_{\mathrm{CE}}=\mathrm{d}_{\mathrm{ZG}}\right) 0.774$ & $\left(\mathrm{~d}_{\mathrm{KD}}=\mathrm{d}_{\mathrm{AA}}\right) \mathbf{0 . 0 0 0}$ & $\left(\mathrm{d}_{\mathrm{MK}}=\mathrm{d}_{\mathrm{CE}}\right) 0.651$ & $\left(\mathrm{~d}_{\mathrm{ZG}}=\mathrm{d}_{\mathrm{KD}}\right) 0.824$ \\
\hline & $\left(\mathrm{d}_{\mathrm{AA}}=\mathrm{d}_{\mathrm{ZG}}\right) \mathbf{0 . 0 0 0}$ & $\left(\mathrm{d}_{\mathrm{CE}}=\mathrm{d}_{\mathrm{AA}}\right) \mathbf{0 . 0 0 0}$ & $\left(\mathrm{d}_{\mathrm{KD}}=\mathrm{d}_{\mathrm{CE}}\right) 0.513$ & $\left(\mathrm{~d}_{\mathrm{MK}}=\mathrm{d}_{\mathrm{KD}}\right) 0.136$ & $\left(\mathrm{~d}_{\mathrm{ZG}}=\mathrm{d}_{\mathrm{MK}}\right) 0.218$ \\
\hline
\end{tabular}

Table 2. As Table 1 for the $\mathrm{M}_{\mathrm{s}}-\mathrm{M}_{\mathrm{w}}$ data set. 


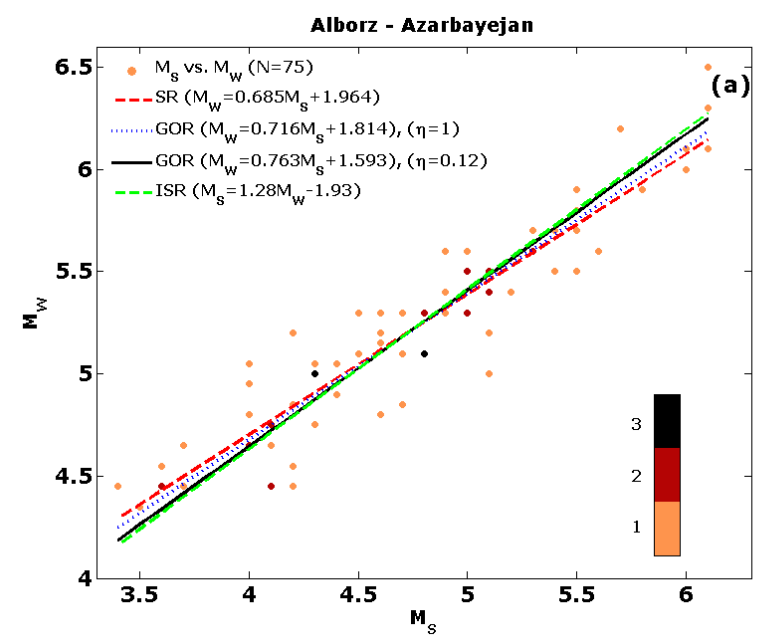

Figure 6 (clockwise from above left). $\mathrm{M}_{\mathrm{S}}-\mathrm{M}_{\mathrm{w}}$ conversion relations for major seismotectonic provinces in Iran $\left(M_{s} \leq 6.1\right)$. Abbreviations as Figure 3.

$\mathrm{R}^{2}=0.88, \sigma=0.16, \mathrm{n}=407,3 \leq \mathrm{M}_{\mathrm{s}} \leq 6.1, \eta=0.12$, for $\mathrm{CE}, \mathrm{KD}, \mathrm{MK}$ and $\mathrm{ZG}$,

$\mathrm{M}_{\mathrm{w}}=0.692( \pm 0.014) \mathrm{M}_{\mathrm{s}}+1.945( \pm 0.071)$,

$\mathrm{R}^{2}=0.88, \sigma=0.16, \mathrm{n}=482,3 \leq \mathrm{M}_{\mathrm{s}} \leq 6.1, \eta=0.12$, for all provinces.

For comparison, conversion relations from SR, ISR, OR and GOR are shown in Figure 6. As shown, the line obtained from the GOR method is located between the OR line and the ISR line, albeit very closer to the ISR line.

\section{3. $m_{b}-M_{S}$}

The conversion relations between $\mathrm{m}_{\mathrm{b}}$ and $\mathrm{M}_{\mathrm{s}}$ are estimated for events where $m_{b} \leq 6.2$ to avoid the saturation effect. Totally, there are 2498 earthquakes for which $\mathrm{m}_{\mathrm{b}}$ and $\mathrm{M}_{\mathrm{s}}$ are both reported. In Sections 4.1 and 4.2, uncertainties of $m_{b}$ and $M_{s}$ for all magnitude range
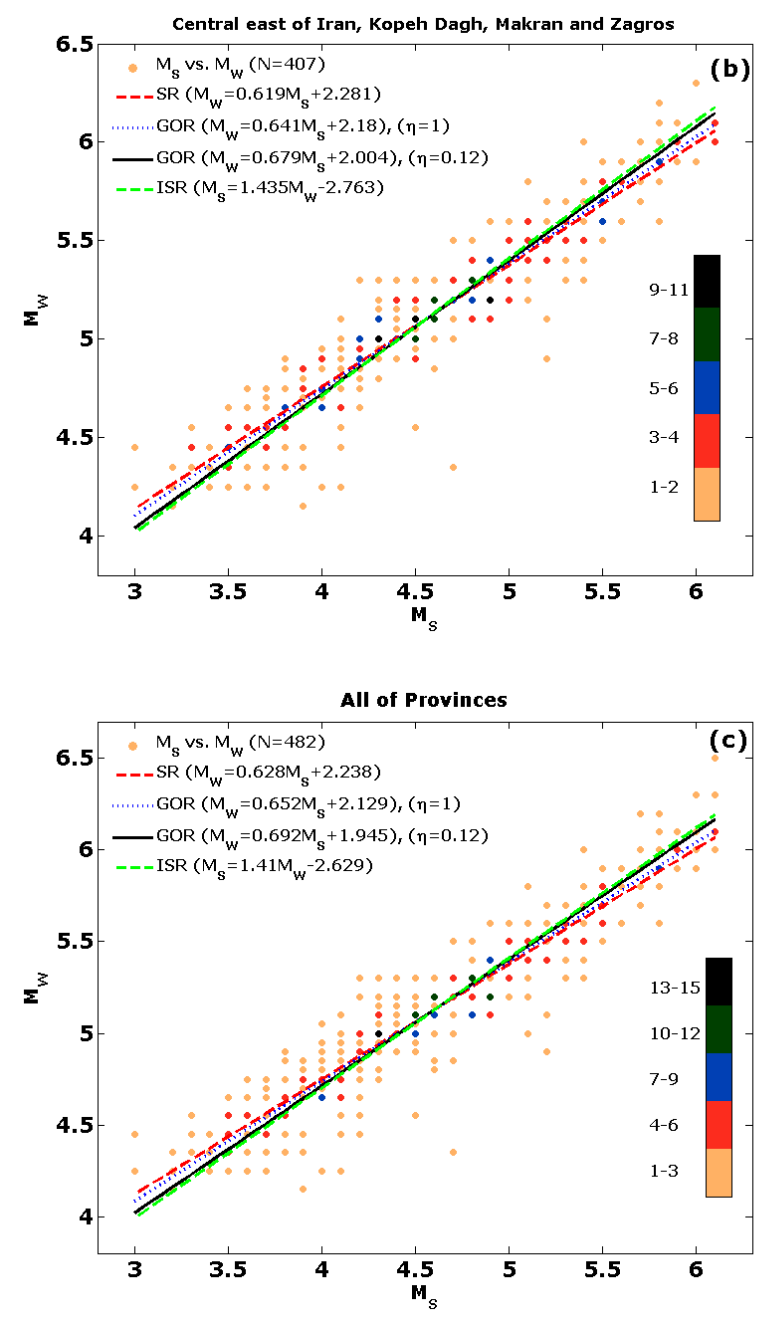

have been estimated to be 0.213 and 0.322 , respectively. The error variances ratio

$$
\eta=\frac{\sigma_{\mathrm{M}_{\mathrm{s}}}^{2}}{\sigma_{\mathrm{m}_{\mathrm{b}}}^{2}}
$$

is estimated to be 2.29 and the square root of $\eta$ is 1.513 . Because this value is between 0.7 and 1.8 , according to Castellaro and Bormann [2007], the OR performs better, as compared with the SR and ISR relations. How-

\begin{tabular}{cccccc}
\hline Data set & $\mathrm{AA}$ & $\mathrm{CE}$ & $\mathrm{KD}$ & $\mathrm{MK}$ & $\mathrm{ZG}$ \\
\hline No. of data & 373 & 443 & 131 & 133 & 1418 \\
Magnitude interval & $3.2 \leq \mathrm{m}_{\mathrm{b}} \leq 6.2$ & $3.4 \leq \mathrm{m}_{\mathrm{b}} \leq 6.2$ & $3.3 \leq \mathrm{m}_{\mathrm{b}} \leq 6.1$ & $3.5 \leq \mathrm{m}_{\mathrm{b}} \leq 5.9$ & $3.3 \leq \mathrm{m}_{\mathrm{b}} \leq 6.2$ \\
Intercept & $-2.444 \pm 0.46$ & $-2.563 \pm 0.354$ & $-2.45 \pm 0.876$ & $-2.467 \pm 0.699$ & $-2.1436 \pm 0.242$ \\
Slope & $1.446 \pm 0.102$ & $1.405 \pm 0.079$ & $1.493 \pm 0.199$ & $1.434 \pm 0.154$ & $1.354 \pm 0.054$ \\
Mean difference & $0.451 \pm 0.047$ & $0.408 \pm 0.045$ & $0.338 \pm 0.085$ & $0.504 \pm 0.073$ & $0.561 \pm 0.023$ \\
\hline & $\left(\mathrm{d}_{\mathrm{AA}}=\mathrm{d}_{\mathrm{CE}}\right) 0.643$ & $\left(\mathrm{~d}_{\mathrm{CE}}=\mathrm{d}_{\mathrm{KD}}\right) 0.524$ & $\left(\mathrm{~d}_{\mathrm{KD}}=\mathrm{d}_{\mathrm{MK}}\right) \mathbf{0 . 0 2 3}$ & $\left(\mathrm{d}_{\mathrm{MK}}=\mathrm{d}_{\mathrm{ZG}}\right) 0.619$ & $\left(\mathrm{~d}_{\mathrm{ZG}}=\mathrm{d}_{\mathrm{AA}}\right) \mathbf{0 . 0 0 0}$ \\
$\begin{array}{c}\text { s.l. for rejecting the } \\
\text { equality of mean } \\
\text { difference d }\end{array}$ & $\left(\mathrm{d}_{\mathrm{AA}}=\mathrm{d}_{\mathrm{KD}}\right) 0.096$ & $\left(\mathrm{~d}_{\mathrm{CE}}=\mathrm{d}_{\mathrm{MK}}\right) 0.194$ & $\left(\mathrm{~d}_{\mathrm{KD}}=\mathrm{d}_{\mathrm{ZG}}\right) \mathbf{0 . 0 0 0}$ & $\left(\mathrm{d}_{\mathrm{MK}}=\mathrm{d}_{\mathrm{AA}}\right) 0.773$ & $\left(\mathbf{d}_{\mathrm{ZG}}=\mathrm{d}_{\mathrm{CE}}\right) \mathbf{0 . 0 0 0}$ \\
& $\left(\mathrm{d}_{\mathrm{AA}}=\mathrm{d}_{\mathrm{MK}}\right) 0.773$ & $\left(\mathrm{~d}_{\mathrm{CE}}=\mathrm{d}_{\mathrm{ZG}}\right) \mathbf{0 . 0 0 0}$ & $\left(\mathrm{d}_{\mathrm{KD}}=\mathrm{d}_{\mathrm{AA}}\right) 0.096$ & $\left(\mathrm{~d}_{\mathrm{MK}}=\mathrm{d}_{\mathrm{CE}}\right) 0.194$ & $\left(\mathrm{~d}_{\mathrm{ZG}}=\mathrm{d}_{\mathrm{KD}}\right) \mathbf{0 . 0 0 0}$ \\
& $\left(\mathrm{d}_{\mathrm{AA}}=\mathrm{d}_{\mathrm{ZG}}\right) \mathbf{0 . 0 0 0}$ & $\left(\mathrm{d}_{\mathrm{CE}}=\mathrm{d}_{\mathrm{AA}}\right) 0.643$ & $\left(\mathrm{~d}_{\mathrm{KD}}=\mathrm{d}_{\mathrm{CE}}\right) 0.524$ & $\left(\mathrm{~d}_{\mathrm{MK}}=\mathrm{d}_{\mathrm{KD}}\right) \mathbf{0 . 0 2 3}$ & $\left(\mathrm{d}_{\mathrm{ZG}}=\mathrm{d}_{\mathrm{MK}}\right) 0.619$ \\
\hline
\end{tabular}

Table 3. As Table 1 for the $m_{b}-M_{s}$ data set. 
ever, we preferred to estimate the $m_{b}-M_{S}$ relations for each seismotectonic province using the GOR method with $\eta=2.29$.

The s.l. for rejecting the $\mathrm{H}_{0}$ hypotheses-the equality of slope coefficients and the equality of mean differences, is estimated to be 0.09 and $<0.001$, respectively. Based on the ANOVA, we can assert that the differences between slope coefficients for the five data sets are not significant and those between mean differences for the five data sets are significant. The results of Tukey test shown in Table 3, indicate that, the mean difference for ZG is significantly different from those for $A A, C E$ and $\mathrm{KD}$ (s.l. for all are $<0.001$ ), but that for $Z G$ is not different from MK data set. On the other hand, the mean differences for $\mathrm{AA}, \mathrm{CE}, \mathrm{KD}$ and $\mathrm{MK}$ are not significantly different (Table 3). Hence, we kept the data from ZG separate and merged the data sets from the four other regions. Eventually, we estimated the $\mathrm{m}_{\mathrm{b}}-\mathrm{M}_{\mathrm{S}}$ relations for three data sets-the first taken from ZG (relation 11), the second taken from four other regions (relation 12) and the third taken from all of them (relation 13), using GOR method.

$\mathrm{M}_{\mathrm{s}}=1.354( \pm 0.024) \mathrm{m}_{\mathrm{b}}-2.143( \pm 0.112)$,

$\mathrm{R}^{2}=0.60, \sigma=0.45, \mathrm{n}=1418,3.3 \leq \mathrm{m}_{\mathrm{b}} \leq 6.2, \eta=2.29$, for ZG

$\mathrm{M}_{\mathrm{s}}=1.464( \pm 0.026) \mathrm{m}_{\mathrm{b}}-2.497( \pm 0.118)$,

$\mathrm{R}^{2}=0.68, \sigma=0.47, \mathrm{n}=1080,3.2 \leq \mathrm{m}_{\mathrm{b}} \leq 6.2, \eta=2.29$, for $\mathrm{AA}, \mathrm{CE}, \mathrm{KD}$ and $\mathrm{MK}$,

$\mathrm{M}_{\mathrm{s}}=1.415( \pm 0.017) \mathrm{m}_{\mathrm{b}}-2.355( \pm 0.082)$,

$\mathrm{R}^{2}=0.63, \sigma=0.46, \mathrm{n}=2498,3.2 \leq \mathrm{m}_{\mathrm{b}} \leq 6.2, \eta=2.29$, for all provinces.

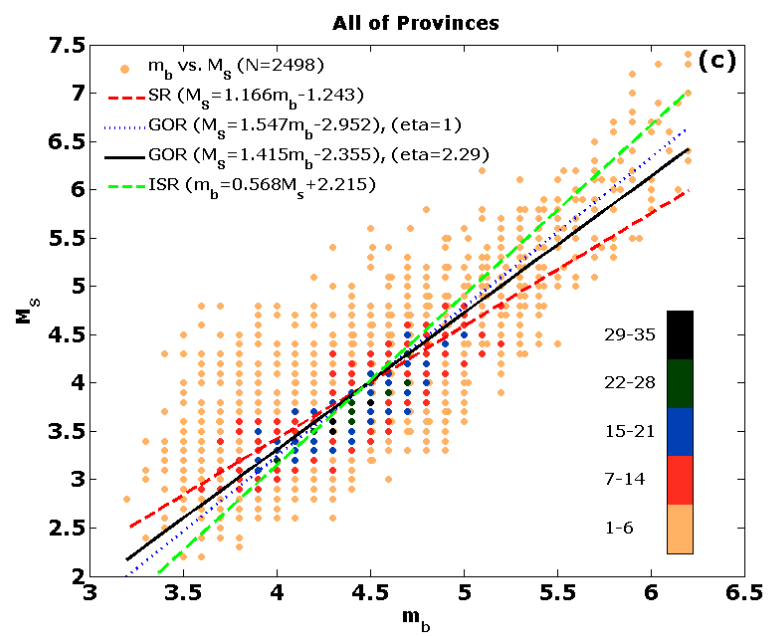

For comparison, conversion relations from SR, ISR, OR and GOR are shown in Figure 7. As shown, the line obtained from the GOR method is located between the OR line and the SR line.

$$
\text { 4.4. } M_{N}-M_{w}
$$

There are 350 earthquakes for which $\mathrm{M}_{N}$ and $\mathrm{M}_{\mathrm{w}}$ are both reported. This data set is divided to two parts - the first part for time interval from 1996 to late 2005 contains 228 events and the second part for 2006 to late 2012 contains 122 events. In the first one, $M_{N}$ has been estimated by relation according to Nuttli [1973], which is accompanied with large errors in location and magnitude. In the second one, $\mathrm{M}_{\mathrm{N}}$ is estimated using modified Nuttli relation proposed by Rezapour [2005]. The standard deviation $\sigma_{\Delta \mathrm{m}}$ of magnitude difference between $\mathrm{M}_{\mathrm{w}}$ and $\mathrm{M}_{\mathrm{N}}$ for the two time intervals 1996 to 2005 and 2006 to 2012 are estimated to be 0.377 and 0.218 , respectively. Using relation 2 and the estimated uncertainty of $\mathrm{M}_{\mathrm{w}}$, the uncertainty of $\mathrm{M}_{\mathrm{N}}$ for the two time intervals are estimated to be 0.363 and 0.193 respectively. The error variances ratios
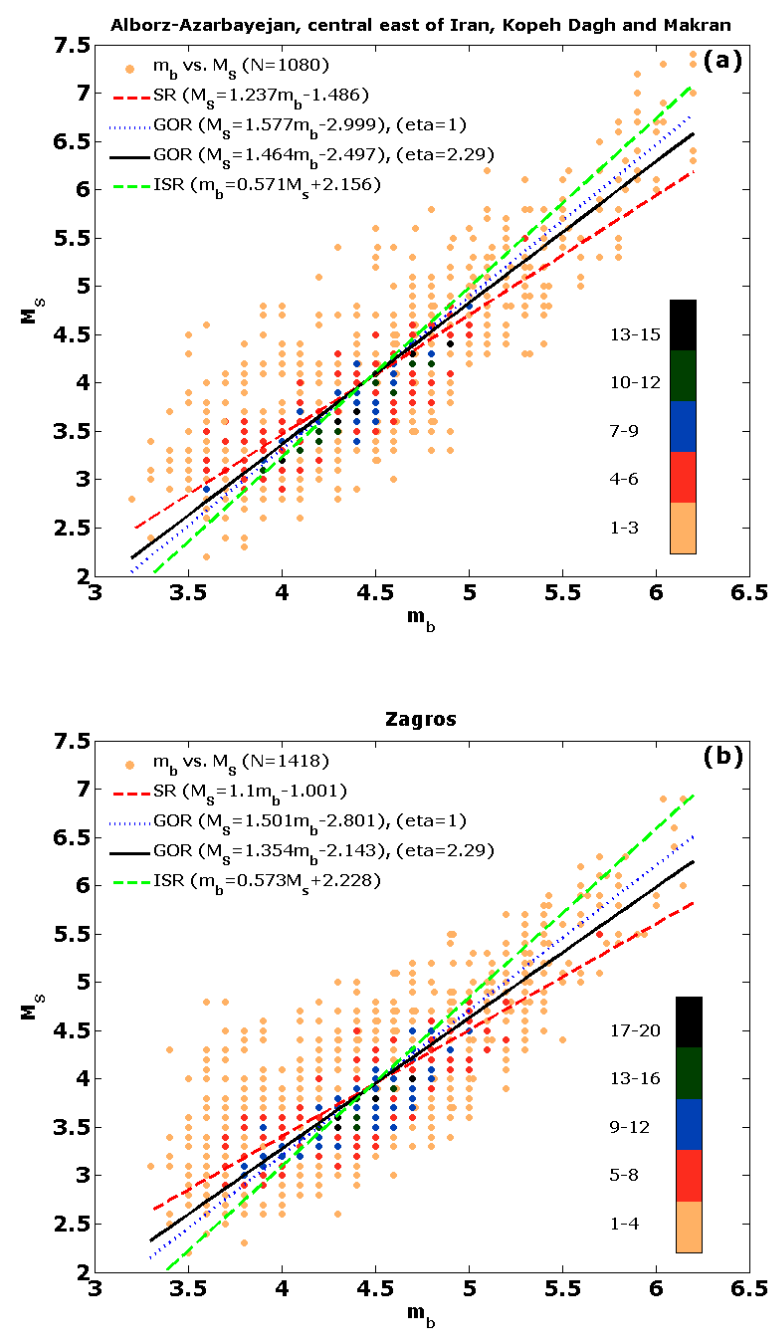

Figure 7 (clockwise from top right). $\mathrm{m}_{\mathrm{b}}-\mathrm{M}_{\mathrm{s}}$ conversion relations for major seismotectonic provinces in Iran. Abbreviations as Figure 3. 


$$
\eta=\frac{\sigma_{\mathrm{M}_{\mathrm{w}}}^{2}}{\sigma_{\mathrm{M}_{\mathrm{N}}}^{2}}
$$

for the two time intervals are estimated to be 0.076 and 0.267 . Because the estimated square root of $\eta$ for the two time intervals are 0.275 and 0.517 , according to Castellaro and Bormann [2007], the ISR performs better, as compared with the SR and the OR relations. However, we preferred to estimate the $\mathrm{M}_{\mathrm{N}}-\mathrm{M}_{\mathrm{w}}$ relations for the two time intervals using the GOR method with estimated $\eta$.

By comparison of s.l. for mean differences and that for slope coefficients in the previous sections, can be concluded that, difference between the data sets in the mean difference terms is clearer than the slope coefficient terms. Thus, to specify statistically difference between the $\mathrm{M}_{\mathrm{N}}-\mathrm{M}_{\mathrm{w}}$ data sets for the five major seismotectonic provinces in Iran, we used the ANOVA to evaluate the significant difference between the mean differences from the five data sets (Table 4). The s.l. for rejecting $\mathrm{H}_{0}$ hypothesis-equality of mean differences for the five regions, are estimated to be 0.08 , that is larger than 0.05 , so, there is not significantly difference between the $\mathrm{M}_{\mathrm{N}}-\mathrm{M}_{\mathrm{w}}$ data sets.

We established $\mathrm{M}_{\mathrm{N}}-\mathrm{M}_{\mathrm{w}}$ relations for the two time intervals using the GOR method with estimated $\eta$.

$\mathrm{M}_{\mathrm{w}}=0.948( \pm 0.045) \mathrm{M}_{\mathrm{N}}+0.664( \pm 0.201)$,

$\mathrm{R}^{2}=0.51, \sigma=0.36, \mathrm{n}=228,3.0 \leq \mathrm{M}_{\mathrm{N}} \leq 6.4, \eta=0.076$, for time interval 1996 to 2005 ,

$\mathrm{M}_{\mathrm{w}}=0.922( \pm 0.044) \mathrm{M}_{\mathrm{N}}+0.494( \pm 0.226)$,

$\mathrm{R}^{2}=0.75, \sigma=0.2, \mathrm{n}=122,4.2 \leq \mathrm{M}_{\mathrm{N}} \leq 7.1, \eta=0.267$, for time interval 2006 to 2012 .

For comparison, conversion relations from the SR, ISR, OR and GOR with the estimated $\eta$ are shown in Figure 8, the line obtained from the GOR method is lo-
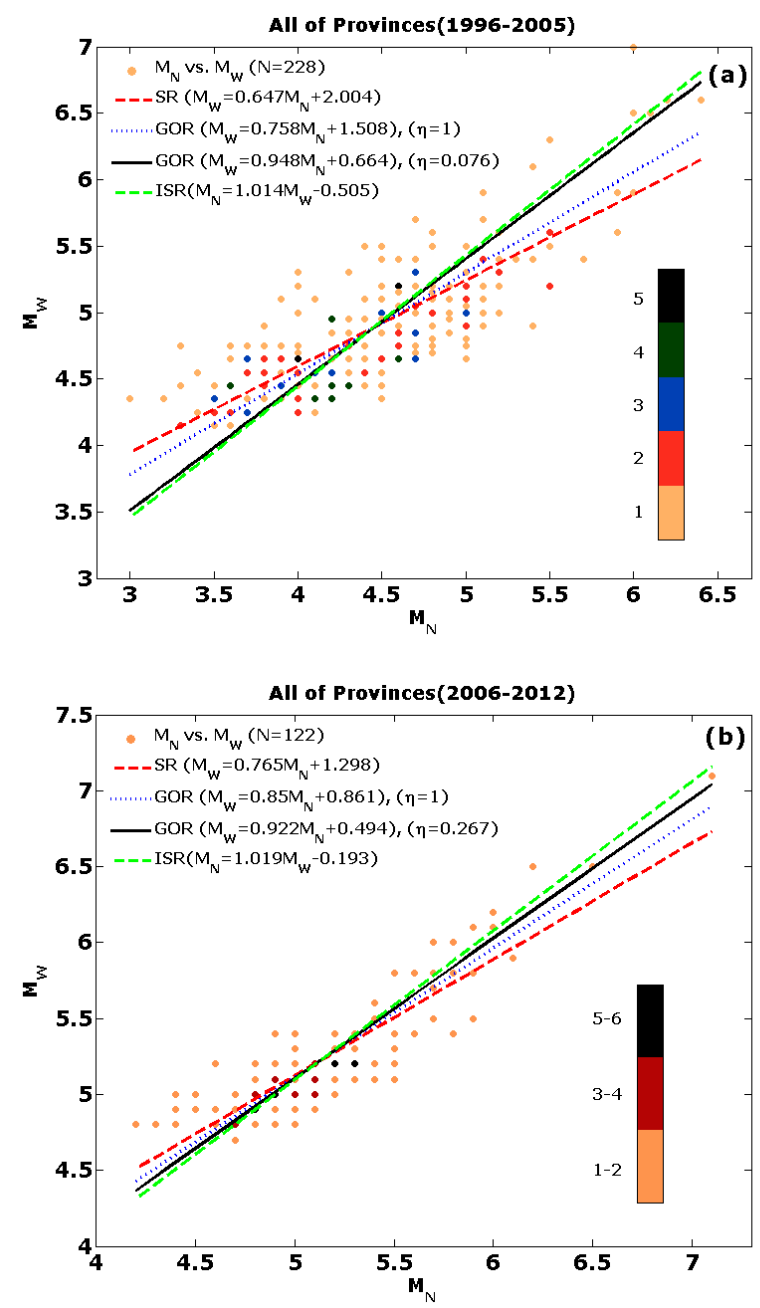

Figure 8. $\mathrm{M}_{\mathrm{N}}-\mathrm{M}_{\mathrm{w}}$ conversion relations for two time intervals based on IRSC data. (a) $\mathrm{M}_{\mathrm{N}}$ has been estimated according to Nuttli [1973] relation. (b) $\mathrm{M}_{\mathrm{N}}$ has been estimated using modified Nuttli relation proposed by Rezapour et al. [2005]. Abbreviations as Figure 3.

cated between the OR line and the ISR line. Few defined $\mathrm{M}_{\mathrm{w}}$ for small earthquakes in Iran are relevant to time interval 1998 to 2005 (by ETHZ) that is synchronic to the first time interval of $\mathrm{M}_{\mathrm{N}}$. So, the data used to estimate $\mathrm{M}_{\mathrm{N}}-\mathrm{M}_{\mathrm{w}}$ for the first time interval are in the range $3.0 \leq \mathrm{M}_{\mathrm{N}} \leq 6.4$ (relation 14). It is noticed that $\mathrm{M}_{\mathrm{N}}-\mathrm{M}_{\mathrm{w}}$ conversion relations underestimate for $\mathrm{M}_{\mathrm{N}}<3.5$ in the first time interval (Figure 8a) and also for $\mathrm{M}_{\mathrm{N}}<4.5$ in

\begin{tabular}{|c|c|c|c|c|c|}
\hline Data set & $\mathrm{AA}$ & $\mathrm{CE}$ & $\mathrm{KD}$ & MK & ZG \\
\hline No. of data & 50 & 44 & 10 & 5 & 241 \\
\hline Mean difference & $0.229 \pm 0.086$ & $0.196 \pm 0.136$ & $0.235 \pm 0.311$ & $0.34 \pm 0.257$ & $0.36 \pm 0.047$ \\
\hline \multirow{4}{*}{$\begin{array}{l}\text { s.1. for rejecting the } \\
\text { equality of mean } \\
\text { difference d }\end{array}$} & $\left(\mathrm{d}_{\mathrm{AA}}=\mathrm{d}_{\mathrm{CE}}\right) 0.973$ & $\left(\mathrm{~d}_{\mathrm{CE}}=\mathrm{d}_{\mathrm{KD}}\right) 0.711$ & $\left(\mathrm{~d}_{\mathrm{KD}}=\mathrm{d}_{\mathrm{MK}}\right) 1.000$ & $\left(\mathrm{~d}_{\mathrm{MK}}=\mathrm{d}_{\mathrm{ZG}}\right) 1.000$ & $\left(\mathrm{~d}_{\mathrm{ZG}}=\mathrm{d}_{\mathrm{AA}}\right) 0.096$ \\
\hline & $\left(\mathrm{d}_{\mathrm{AA}}=\mathrm{d}_{\mathrm{KD}}\right) 0.891$ & $\left(\mathrm{~d}_{\mathrm{CE}}=\mathrm{d}_{\mathrm{MK}}\right) 0.868$ & $\left(\mathrm{~d}_{\mathrm{KD}}=\mathrm{d}_{\mathrm{ZG}}\right) 1.000$ & $\left(\mathrm{~d}_{\mathrm{MK}}=\mathrm{d}_{\mathrm{AA}}\right) 0.955$ & $\left(\mathrm{~d}_{\mathrm{ZG}}=\mathrm{d}_{\mathrm{CE}}\right) 0.055$ \\
\hline & $\left(\mathrm{d}_{\mathrm{AA}}=\mathrm{d}_{\mathrm{MK}}\right) 0.955$ & $\left(\mathrm{~d}_{\mathrm{CE}}=\mathrm{d}_{\mathrm{ZG}}\right) 0.055$ & $\left(\mathrm{~d}_{\mathrm{KD}}=\mathrm{d}_{\mathrm{AA}}\right) 0.891$ & $\left(\mathrm{~d}_{\mathrm{MK}}=\mathrm{d}_{\mathrm{CE}}\right) 0.868$ & $\left(\mathrm{~d}_{\mathrm{ZG}}=\mathrm{d}_{\mathrm{KD}}\right) 1.000$ \\
\hline & $\left(\mathrm{d}_{\mathrm{AA}}=\mathrm{d}_{\mathrm{ZG}}\right) 0.096$ & $\left(\mathrm{~d}_{\mathrm{CE}}=\mathrm{d}_{\mathrm{AA}}\right) 0.973$ & $\left(\mathrm{~d}_{\mathrm{KD}}=\mathrm{d}_{\mathrm{CE}}\right) 0.711$ & $\left(\mathrm{~d}_{\mathrm{MK}}=\mathrm{d}_{\mathrm{KD}}\right) 1.000$ & $\left(\mathrm{~d}_{\mathrm{ZG}}=\mathrm{d}_{\mathrm{MK}}\right) 1.000$ \\
\hline
\end{tabular}

Table 4. As Table 1 for mean differences of the $\mathrm{M}_{\mathrm{N}}-\mathrm{M}_{\mathrm{w}}$ data set. 


\begin{tabular}{cccccc}
\hline Data set & $\mathrm{AA}$ & $\mathrm{CE}$ & $\mathrm{KD}$ & $\mathrm{MK}$ & $\mathrm{ZG}$ \\
\hline No. of data & 12 & 21 & 3 & 3 & 84 \\
Mean difference & $0.067 \pm 0.202$ & $0.05 \pm 0.091$ & $0.017 \pm 0.399$ & $0.067 \pm 0.799$ & $0.227 \pm 0.05$ \\
\hline $\begin{array}{c}\text { s.l. for rejecting the } \\
\text { equality of mean } \\
\text { difference d }\end{array}$ & $\left(\mathrm{d}_{\mathrm{AA}}=\mathrm{d}_{\mathrm{CE}}\right) 1.000$ & $\left(\mathrm{~d}_{\mathrm{CE}}=\mathrm{d}_{\mathrm{KD}}\right) 0.999$ & $\left(\mathrm{~d}_{\mathrm{KD}}=\mathrm{d}_{\mathrm{MK}}\right) 0.999$ & $\left(\mathrm{~d}_{\mathrm{MK}}=\mathrm{d}_{\mathrm{ZG}}\right) 0.781$ & $\left(\mathrm{~d}_{\mathrm{ZG}}=\mathrm{d}_{\mathrm{AA}}\right) 0.193$ \\
& $\left(\mathrm{~d}_{\mathrm{AA}}=\mathrm{d}_{\mathrm{MK}}\right) 1.000$ & $\left(\mathrm{~d}_{\mathrm{CE}}=\mathrm{d}_{\mathrm{MK}}\right) 1.000$ & $\left(\mathrm{~d}_{\mathrm{KD}}=\mathrm{d}_{\mathrm{ZG}}\right) 0.561$ & $\left(\mathrm{~d}_{\mathrm{MK}}=\mathrm{d}_{\mathrm{AA}}\right) 1.000$ & $\left(\mathrm{~d}_{\mathrm{ZG}}=\mathrm{d}_{\mathrm{CE}}\right) \mathbf{0 . 0 2 3}$ \\
& $\left(\mathrm{d}_{\mathrm{AA}}=\mathrm{d}_{\mathrm{ZG}}\right) 0.193$ & $\left(\mathrm{~d}_{\mathrm{CE}}=\mathrm{d}_{\mathrm{AA}}\right) 1.000$ & $\left(\mathrm{~d}_{\mathrm{KD}}=\mathrm{d}_{\mathrm{CE}}\right) 0.999$ & $\left(\mathrm{~d}_{\mathrm{MK}}=\mathrm{d}_{\mathrm{KD}}\right) 0.999$ & $\left(\mathrm{~d}_{\mathrm{ZG}}=\mathrm{d}_{\mathrm{MK}}\right) 0.781$ \\
\hline
\end{tabular}

Table 5. As Table 1 for mean differences of the $M_{L}-M_{w}$ data set.

the second time interval (Figure $8 \mathrm{~b}$ ).

$$
\text { 4.5. } M_{L}-M_{w}
$$

There are 123 earthquakes in the catalog for which $\mathrm{M}_{\mathrm{L}}$ and $\mathrm{M}_{\mathrm{w}}$ are both reported. The standard deviation of magnitude difference between $\mathrm{M}_{\mathrm{w}}$ and $\mathrm{M}_{\mathrm{L}}$ is estimated to be 0.247 . Using the relation 2 and the estimated uncertainty of $M_{w}$, the uncertainty of $M_{L}$ is estimated to be 0.226 . The variances ratio

$$
\eta=\frac{\sigma_{\mathrm{M}_{\mathrm{w}}}^{2}}{\sigma_{\mathrm{M}_{\mathrm{L}}}^{2}}
$$

is estimated to be 0.196 . Because the estimated square root of $\eta$ is 0.442 , according to Castellaro and Bormann [2007], the ISR performs better, as compared with the SR and the OR relations.

In order to specify significantly difference between $M_{L}-M_{w}$ data sets for the five major seismotectonic provinces in Iran, we used the ANOVA to determine the significant difference between the mean differences of the five data sets (Table 5). The s.l. for rejecting $\mathrm{H}_{0}$ hypothesis-equality of mean differences for the five regions, are estimated to be 0.009 , that is less than 0.05 , but despite significantly difference between CE and ZG

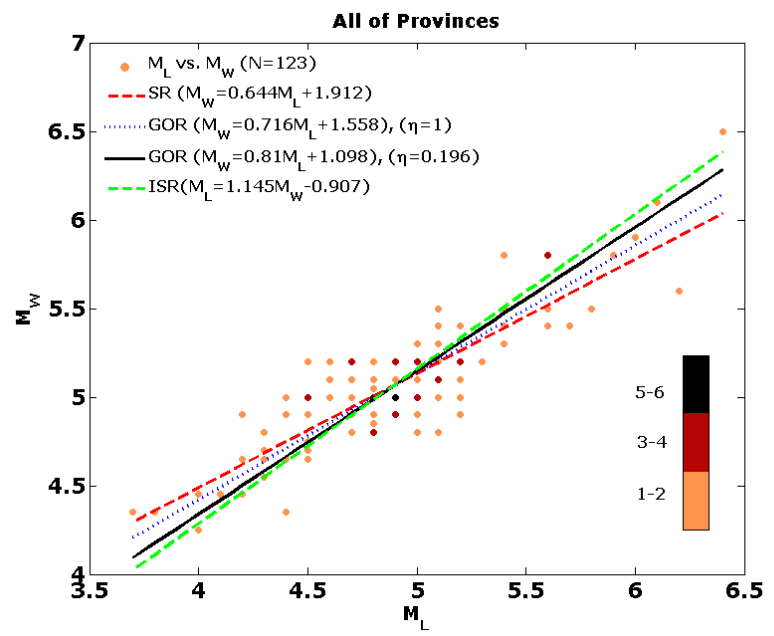

Figure 9. $\mathrm{M}_{\mathrm{L}}-\mathrm{M}_{\mathrm{w}}$ conversion relations for Iran. Abbreviations as Figure 3. data sets, Tukey test don't suggest separation of the data set to two or more parts. We estimated the $M_{L}-M_{w}$ relation for all of data set using the GOR with the estimated $\eta$.

$\mathrm{M}_{\mathrm{w}}=0.81( \pm 0.045) \mathrm{M}_{\mathrm{L}}+1.098( \pm 0.22)$

$\mathrm{R}^{2}=0.69, \sigma=0.2, \mathrm{n}=123,3.7 \leq \mathrm{M}_{\mathrm{L}} \leq 6.4, \eta=0.196$, for all provinces.

For comparison, conversion relations of $\mathrm{M}_{\mathrm{L}}-\mathrm{M}_{\mathrm{w}}$ from SR, ISR, OR and GOR are shown in Figure 9. As shown, the line obtained from the GOR method is located between the OR line and ISR line. Comparisons between derived regressions in this study with previous studies are presented in Figure 10.

4.6. Which conversion relations should be deployed to unify the catalog?

In order to unify the catalog to $\mathrm{M}_{\mathrm{w}}$, if the $\mathrm{M}_{\mathrm{w}}$ of an event is available it is used directly. Otherwise, conversion relations are used in the order of priority given in Table 6 . In Table 6 the coefficients of determination $\mathrm{R}^{2}$ values are used as a criterion to determine which models are preferred. In order to unify the catalog in terms of $M_{s}$, we applied $m_{b}-M_{s}$ relations for the relevant re-

\begin{tabular}{ccc}
\hline Priority No. & Model & $\begin{array}{c}\text { Relation No. and } \mathrm{R}^{2} \\
\text { (within parentheses) }\end{array}$ \\
\hline 1 & $\mathrm{M}_{\mathrm{s}}-\mathrm{M}_{\mathrm{w}}$ & $\begin{array}{c}7(0.76), 8(0.84) \\
\text { and } 9(0.88)\end{array}$ \\
2 & $\mathrm{~m}_{\mathrm{b}}-\mathrm{M}_{\mathrm{w}}$ & $\begin{array}{c}4(0.73) \\
\text { and } 5(0.80)\end{array}$ \\
3 & $\mathrm{M}_{\mathrm{N}}-\mathrm{M}_{\mathrm{w}}$ & $15(0.75)$ \\
4 & $\mathrm{M}_{\mathrm{L}}-\mathrm{M}_{\mathrm{w}}$ & $16(0.69)$ \\
5 & $\mathrm{M}_{\mathrm{N}}-\mathrm{M}_{\mathrm{w}}$ & $14(0.51)$ \\
\hline
\end{tabular}

Table 6. Magnitude conversion relations applied to unify the cata$\log$ in order of priority. 
gion (relations 11 or 12). For events outside the seismotectonic provinces, the conversion relation of the nearest region is applied.

The final unified catalog is presented in electronic Supplement (1). In the supplement file, the number of the conversion relation used for unification can be found in the reference column.

\subsection{Magnitude uncertainty in the uniform catalog}

Mirzaei et al. [1997] determined, based on the quality and quantity of available information, the uncertainty of earthquake parameters for Iran in three periods of time: the historical period (pre-1900) for which information is obtained from historical documents and field observations, and for which magnitude uncertainty varies from 0.4 to 0.8 magnitude units; for the early instrumental period (1900-1963), for which macroseismic information together with the low quality instrumental data are used to determine different earthquake parameters, with 0.3 to 0.5 magnitude units of uncertainty; and for the modern instrumental period (1964-1994) with 0.2 to 0.4 magnitude units of uncertainty. For some earthquakes in Iran, agencies and case studies reported the uncertainty of $\mathrm{M}_{\mathrm{w}}$. For other earthquakes for which $M_{w}$ has been reported or considered equal to $M_{s}$ (for historical earthquakes), we cautiously assumed the uncertainty of $\mathrm{M}_{\mathrm{w}}$ with respect to the proposal by Mirzaei et al. [1997].

Ordinary conversion relations are used for unifying the catalog with respect to $M_{w}$ as a quantity with well- defined physical meaning. Thus, when evaluating $\mathrm{M}_{\mathrm{w}}$ uncertainty two factors must be gauged: the uncertainty of the original magnitude and any error in transforming the original magnitude into $\mathrm{M}_{\mathrm{w}}$. According to Grünthal et al. [2009] the uncertainties of all conversion relations are given in terms of the $68 \%$ confidence bounds for a predicted value. This measure depends on the residuals between the model and the input data and the covariance of the regression parameters. The difference between the regression relation and its $68 \%$ confidence bounds is approximately one standard deviation of a predicted magnitude [Grünthal et al. 2009]. Usually, the conversion relations used to unify the catalog take this form:

$$
\mathrm{M}_{\mathrm{w}}=a \mathrm{M}_{\text {original }}+b,
$$

where $a$ and $b$ are the dependent parameters with error, and $\mathrm{M}_{\text {original }}$ is the independent variable that can be $\mathrm{m}_{\mathrm{b}}$, $\mathrm{M}_{\mathrm{s}}, \mathrm{M}_{\mathrm{N}}$, or $\mathrm{M}_{\mathrm{L}}$. Taylor [1997] describes how to compute the uncertainty of a function containing dependent variables; for instance, the standard deviation $\sigma$ of $\mathrm{M}_{\mathrm{w}}$ is calculated as below:

$$
\begin{aligned}
& \sigma_{\mathrm{M}_{\mathrm{w}}}= \\
& =\sqrt{a^{2} \sigma_{\mathrm{M}_{\text {original }}}^{2}+\mathrm{M}_{\text {original }}^{2} \sigma_{a}^{2}+\sigma_{b}^{2}+2 \mathrm{M}_{\text {original }} \operatorname{cov}(a, b)},
\end{aligned}
$$

in which $\sigma_{\mathrm{M}_{\text {original }}}$ is the standard deviation of $\mathrm{m}_{\mathrm{b}}, \mathrm{M}_{\mathrm{s}}$, $\mathrm{M}_{\mathrm{N}}$, or $\mathrm{M}_{\mathrm{L}} ; \sigma_{a}$ and $\sigma_{b}$ are the standard deviations of $a$

\begin{tabular}{lllllll}
\hline $\begin{array}{l}\text { Relation } \\
\text { No. }\end{array}$ & $\sigma_{\mathrm{m}_{\text {orginal }}}$ & $\sigma_{a}^{2}$ & $\sigma_{\mathrm{b}}^{2}$ & $\operatorname{Cov}(a, b)$ & Error equation & Error range $(\sigma)$ \\
\hline 4 & 0.213 & 0.0015 & 0.0371 & -0.0075 & $\sigma_{\mathrm{M}_{\mathrm{w}}}=\left[\left(0.15 \mathrm{~m}_{\mathrm{b}}^{2}-1.5 \mathrm{~m}_{\mathrm{b}}+10.32\right) \times 10^{-2}\right]^{1 / 2}$ & $0.2563-0.2598$ \\
5 & 0.213 & 0.0023 & 0.0606 & -0.0117 & $\sigma_{\mathrm{M}_{\mathrm{w}}}=\left[\left(0.23 \mathrm{~m}_{\mathrm{b}}^{2}-2.34 \mathrm{~m}_{\mathrm{b}}+14.11\right) \times 10^{-2}\right]^{1 / 2}$ & $0.2903-0.2906$ \\
6 & 0.213 & 0.0009 & 0.0231 & -0.0046 & $\sigma_{\mathrm{M}_{\mathrm{w}}}=\left[\left(0.09 \mathrm{~m}_{\mathrm{b}}^{2}-0.92 \mathrm{~m}_{\mathrm{b}}+9.95\right) \times 10^{-2}\right]^{1 / 2}$ & $0.2777-0.2781$ \\
7 & 0.185 & 0.0089 & 0.4056 & -0.0601 & $\sigma_{\mathrm{M}_{\mathrm{w}}}=\left[\left(0.89 \mathrm{M}_{\mathrm{s}}^{2}-12.02 \mathrm{M}_{\mathrm{s}}+43.7\right) \times 10^{-2}\right]^{1 / 2}$ & $0.1841-0.2175$ \\
8 & 0.289 & 0.0019 & 0.0436 & -0.0090 & $\sigma_{\mathrm{M}_{\mathrm{w}}}=\left[\left(0.19 \mathrm{M}_{\mathrm{s}}^{2}-1.8 \mathrm{M}_{\mathrm{s}}+9.22\right) \times 10^{-2}\right]^{1 / 2}$ & $0.2302-0.2305$ \\
9 & 0.289 & 0.0003 & 0.0057 & -0.0012 & $\sigma_{\mathrm{M}_{\mathrm{w}}}=\left[\left(0.03 \mathrm{M}_{\mathrm{s}}^{2}-0.24 \mathrm{M}_{\mathrm{s}}+4.42\right) \times 10^{-2}\right]^{1 / 2}$ & $0.1993-0.2018$ \\
10 & 0.289 & 0.0002 & 0.0050 & -0.0011 & $\sigma_{\mathrm{M}_{\mathrm{w}}}=\left[\left(0.02 \mathrm{M}_{\mathrm{s}}^{2}-0.22 \mathrm{M}_{\mathrm{s}}+4.5\right) \times 10^{-2}\right]^{1 / 2}$ & $0.1975-0.2005$ \\
11 & 0.213 & 0.0006 & 0.0126 & -0.0028 & $\sigma_{\mathrm{M}_{\mathrm{w}}}=\left[\left(0.06 \mathrm{~m}_{\mathrm{b}}^{2}-0.56 \mathrm{~m}_{\mathrm{b}}+9.58\right) \times 10^{-2}\right]^{1 / 2}$ & $0.2895-0.2900$ \\
12 & 0.213 & 0.0007 & 0.0139 & -0.0031 & $\sigma_{\mathrm{M}_{\mathrm{w}}}=\left[\left(0.07 \mathrm{~m}_{\mathrm{b}}^{2}-0.62 \mathrm{~m}_{\mathrm{b}}+11.11\right) \times 10^{-2}\right]^{1 / 2}$ & $0.3138-0.3156$ \\
13 & 0.213 & 0.0003 & 0.0067 & -0.0015 & $\sigma_{\mathrm{M}_{\mathrm{w}}}=\left[\left(0.03 \mathrm{~m}_{\mathrm{b}}^{2}-0.3 \mathrm{~m}_{\mathrm{b}}+9.75\right) \times 10^{-2}\right]^{1 / 2}$ & $0.3008-0.3017$ \\
14 & 0.363 & 0.0020 & 0.0403 & -0.0089 & $\sigma_{\mathrm{M}_{\mathrm{w}}}=\left[\left(0.2 \mathrm{M}_{\mathrm{N}}^{2}-1.78 \mathrm{M}_{\mathrm{N}}+15.9\right) \times 10^{-2}\right]^{1 / 2}$ & $0.3515-0.3524$ \\
15 & 0.193 & 0.0019 & 0.0510 & -0.0099 & $\sigma_{\mathrm{M}_{\mathrm{w}}}=\left[\left(0.19 \mathrm{M}_{\mathrm{N}}^{2}-1.98 \mathrm{M}_{\mathrm{N}}+8.27\right) \times 10^{-2}\right]^{1 / 2}$ & $0.1807-0.1946$ \\
16 & 0.226 & 0.0020 & 0.0485 & -0.0099 & $\sigma_{\mathrm{M}_{\mathrm{w}}}=\left[\left(0.2 \mathrm{M}_{\mathrm{L}}^{2}-1.98 \mathrm{M}_{\mathrm{L}}+8.2\right) \times 10^{-2}\right]^{1 / 2}$ & $0.1901-0.1929$ \\
\hline
\end{tabular}

Table 7. Full error equations for the conversion relations of this study ( $\sigma \approx 68 \%$ prediction error). 
and $b$; and $\operatorname{cov}(a, b)$ is the covariance of $\mathrm{a}$ and $\mathrm{b}$ in relation 17. The error equation (relation 18) is used by Grünthal et al. [2009] and Gasperini et al. [2013] and completely explained in Gasperini et al. [2013]. Error equations for all estimated conversion relations in the text are presented in Table 7. We evaluated the standard deviation $\sigma_{\mathrm{M}_{\mathrm{w}}}$ for all unified $\mathrm{M}_{\mathrm{w}}$ using the relevant error equation.
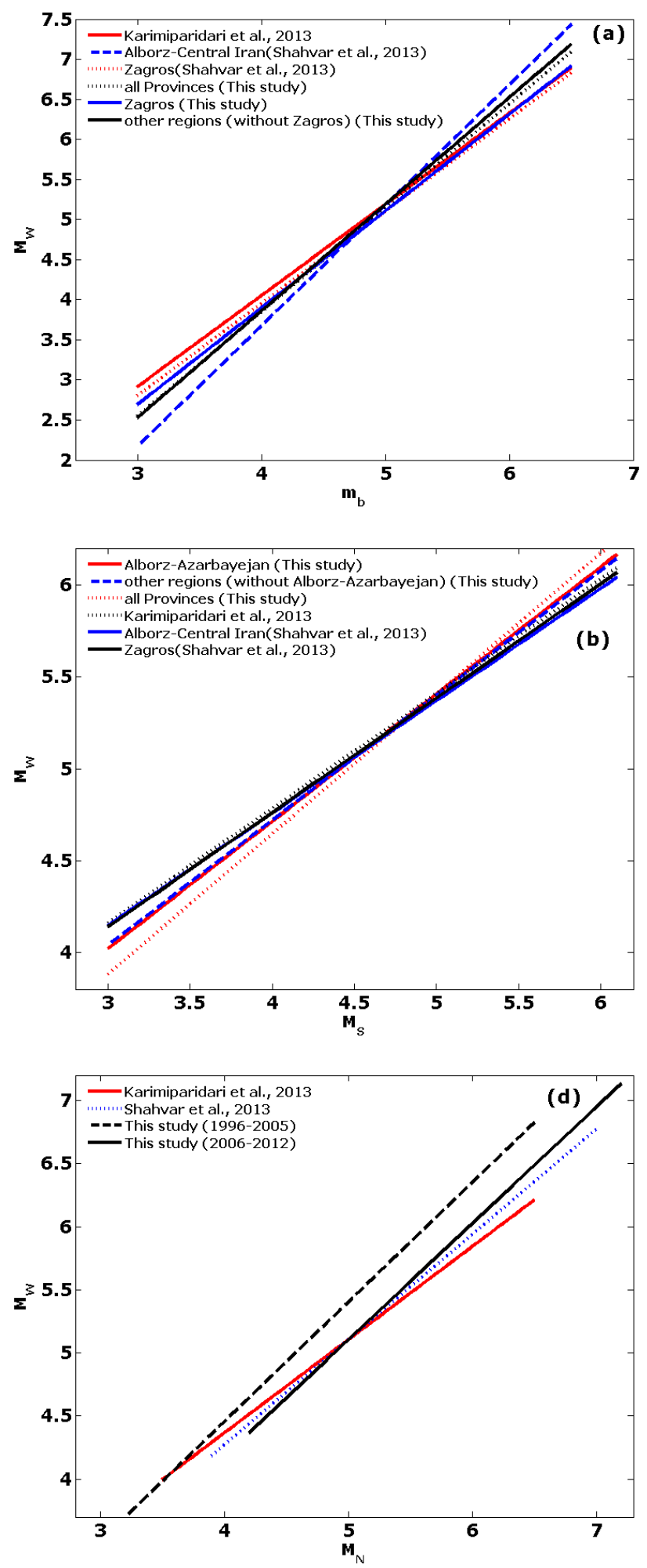

In the supplement file, the uncertainty of $M_{w}$ is given in two separate columns - assumed uncertainty for the reported $\mathrm{M}_{\mathrm{w}}$ and one standard deviation for the converted $\mathrm{M}_{\mathrm{w}}$.

\section{Declustering the catalog}

Dependent (non-Poissonian) earthquakes were removed to achieve a random data set, this is necessary in any time-independent seismic hazard assessment [Pelaez et al. 2007]. In this work, dependent events were identified using two classical sliding-time-and-distance algorithms (windowing routines) proposed by Gardner and Knopoff [1974] and Uhrhammer [1986].

According to Knopoff et al. [1982] if we use large windows, the foreshocks and aftershocks of a given earthquake may be increasingly contaminated by earthquakes belonging to other clusters. When the size of the window is reduced, some dependent events are no longer identified. The aftershock identification windows can vary substantially from one study to another and usually do not result from an optimization procedure [Van Stiphout et al. 2012].
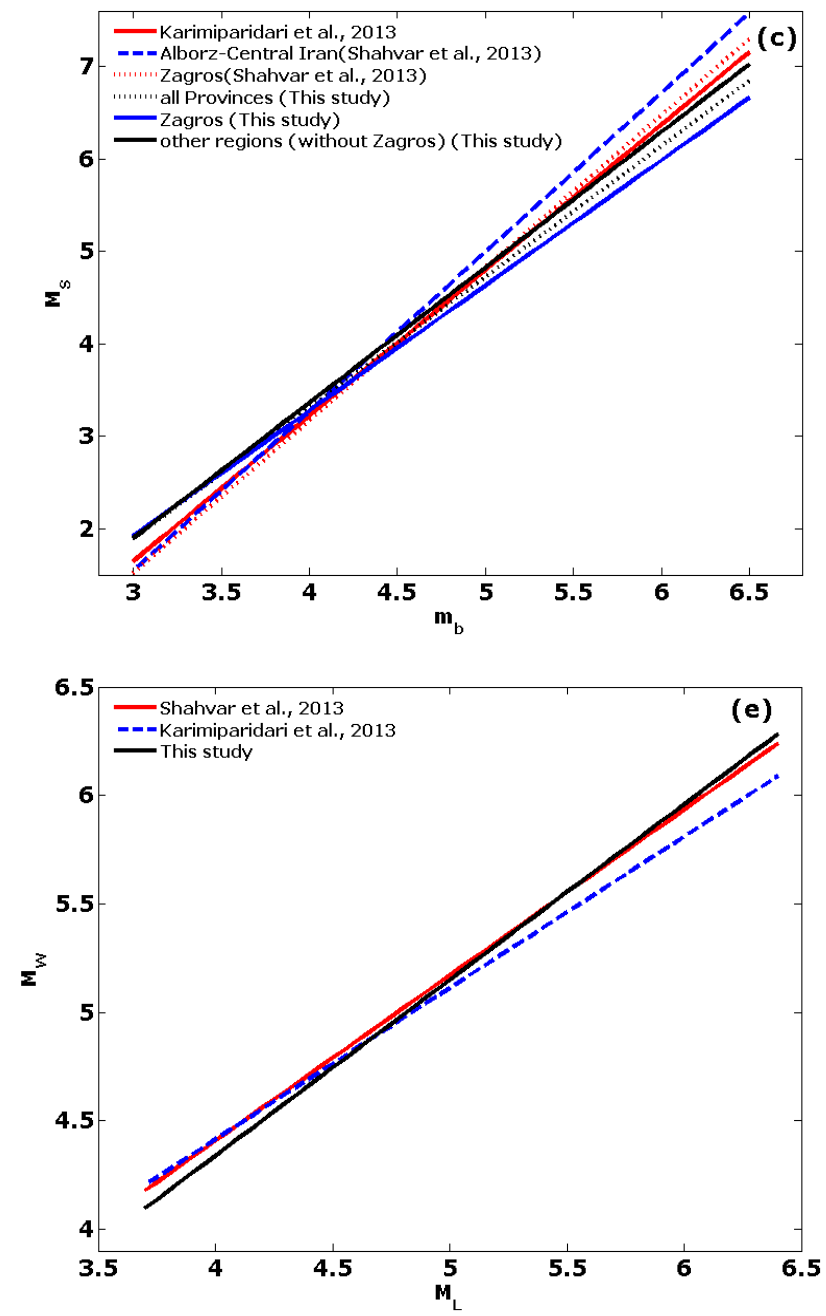

Figure 10. Comparison of magnitude conversion relations, this study and the other studies. 
The size of time and distance windows $\left(\mathrm{L}_{1}, \mathrm{~T}_{1}\right)$ in Uhrhammer [1986] method are presented in Equations (19a) and (19b). The size of time and distance windows $\left(\mathrm{L}_{2}, \mathrm{~T}_{2}\right)$ in Gardner and Knopoff [1974] method are presented in Equations 20a and 20b [Van Stiphout et al. 2012],

$$
\begin{aligned}
& \mathrm{L}_{1}(\mathrm{~km})=\mathrm{e}^{-1.024+0.804 \mathrm{M}_{\mathrm{w}}} \\
& \mathrm{T}_{1}(\text { days })=\mathrm{e}^{-2.87+1.235 \mathrm{M}_{\mathrm{w}}} \\
& \mathrm{L}_{2}(\mathrm{~km})=10^{0.1238 \mathrm{M}_{\mathrm{w}}+0.983} \\
& \mathrm{~T}_{2}(\text { days })= \begin{cases}10^{0.032 \mathrm{M}_{\mathrm{w}}+2.7389} & \text { if } \mathrm{M}_{\mathrm{w}} \geq 6.5 \\
10^{0.5409 \mathrm{M}_{\mathrm{w}}-0.547} & \text { if } \mathrm{M}_{\mathrm{w}}<6.5\end{cases}
\end{aligned}
$$

where $\mathrm{L}_{1}$ and $\mathrm{L}_{2}$ are distance windows in kilometers and $T_{1}$ and $T_{2}$ are time windows in days and $M_{w}$ is mainshock magnitude. Aftershock identification windows in distance and time are depicted in Figure 11 as functions of the mainshock magnitude. Figure 11 shows that, for magnitudes less than $6.3, \mathrm{~L}_{1}$ is smaller than $\mathrm{L}_{2}$, and for magnitudes larger than $6.3, \mathrm{~L}_{1}$ is larger than $\mathrm{L}_{2}$ (Figure 11a). For all magnitudes $T_{1}$ is smaller than $T_{2}$ (Figure 11b). Table 8 presents the time and distance windows for magnitudes ranging from 3.5 to 8 .

We used three steps in declustering data. i) We distinguished all earthquakes to be aftershocks with magnitudes less than $\mathrm{M}_{\mathrm{w}}$ occurred within $\mathrm{T}_{1}$ and $\mathrm{L}_{1}$ for $M_{w} \leq 6.3$ and $T_{1}$ and $L_{2}$ for $M_{w}>6.3$. These events are confined in the cross hatched regions in Figure 11a and Figure 11b. ii) Then, we applied larger windows $T_{2}$ and $L_{2}$ for $M_{w} \leq 6.3$ and $T_{2}$ and $L_{1}$ for $M_{w}>6.3$ to specify events occurred between these two windows (hatched region in Figure 11a and Figure 11b). iii) As the spatial and temporal extents of aftershock sequences vary widely from event to event [Reasenberg 1985], some events placed between the two windows marked to be aftershocks. In the last step we considered temporal and spatial difference in error of earthquake location and disparity in the time range of aftershocks in Iran. Thus, unlike the common studies in this field, as Karimiparidari et al. [2013], instead of assuming the similarity in aftershock sequences, somewhat difference in extents of aftershock sequences is considered. It seems that, using conjugate windows can optimize declustering. In this way, 2091 events out of 10,043 events in the catalog are confined in the smaller windows considered to be aftershocks. A number of 841 events placed between small and large windows, from which 540 events identified as aftershocks. Thus, about $26.2 \%$ of the events in the catalog are considered as aftershocks. This method identified 711 clusters with 2 to 182 dependent events.
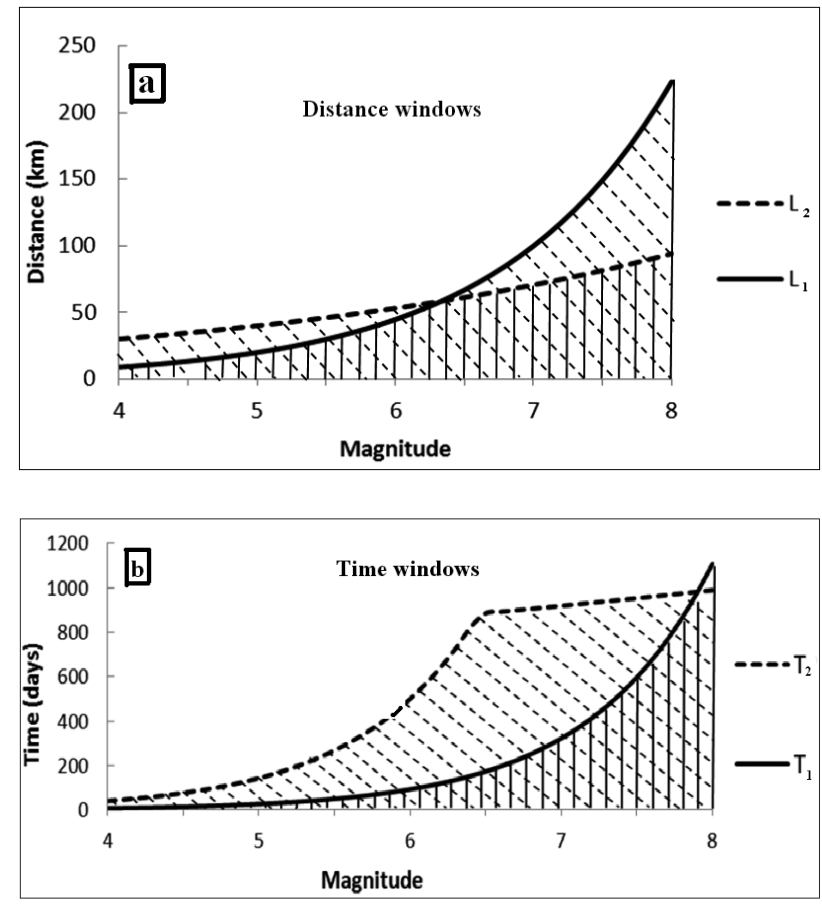

Figure 11. Aftershock identification windows in distance domain (a) and time domain (b) as a function of the mainshock magnitude. The solid lines indicate the original parameter values according to Uhrhammer [1986] and the dashed lines indicate the original parameter values according to Gardner and Knopoff [1974].

\begin{tabular}{ccccc}
\hline Magnitude & $\mathrm{L}_{1}(\mathrm{~km})$ & $\mathrm{L}_{2}(\mathrm{~km})$ & $\mathrm{T}_{1}($ days $)$ & $\mathrm{T}_{2}($ days $)$ \\
\hline 3.5 & 6 & 26 & 4 & 22 \\
4.0 & 9 & 30 & 8 & 42 \\
4.5 & 13 & 35 & 15 & 83 \\
5.0 & 20 & 40 & 27 & 155 \\
5.5 & 30 & 47 & 51 & 290 \\
6.0 & 45 & 54 & 94 & 510 \\
6.5 & 67 & 61 & 174 & 790 \\
7.0 & 100 & 70 & 322 & 915 \\
7.5 & 149 & 81 & 597 & 960 \\
8.0 & 223 & 94 & 1108 & 985 \\
\hline
\end{tabular}

Table 8. Aftershock identification windows, $\mathrm{T}_{1}$ and $\mathrm{L}_{1}$ are time and distance windows according to Uhrhammer [1986], $\mathrm{T}_{2}$ and $\mathrm{L}_{2}$ are time and distance windows according to Gardner and Knopoff [1974].

For comparison of results with the other method we also declustered the catalog by cluster method [Reasenberg 1985], using the ZMAP package [Wiemer 2001]. Van Stiphout et al. [2012] determined ranges for the parameters relevant to Reasenberg's method; used for the simulations in the $\chi^{2}$ goodness of fit test to determine how well they fit a Poisson distribution of parameters. In this study, minimum and maximum values 
of ranges for the parameters proposed by Van Stiphout et al. [2012] are used to decluster the catalog. The results of applied methods to decluster the catalog are summarized in Table 9. We inspected the result of declustering by Reasenberg method by some aftershock sequences as, Qir-Karzin earthquake 10/4/1972 $M_{w}$ 6.9, Tabas-Golshan earthquake $16 / 9 / 1978 M_{w}$ 7.4, Bam earthquake $26 / 12 / 2003 \mathrm{M}_{\mathrm{w}} 6.6$ and Zarand earthquake $22 / 2 / 2005 M_{w}$ 6.4. In all cases, a large number of aftershocks in the declustered catalog remained. For instance, from the 53 aftershocks of Bam earthquake in the catalog, 18 events have remained in the declustered catalog by Reasenberg's method. Also, from the 27 aftershocks of Zarand earthquake in the catalog, 10 events have remained in the declustered catalog by Reasenberg's method. Therefore, we prefer to use our conjugate windows method to decluster the catalog.

Figure 12 shows the epicenters of historical (pre-1900) and independent instrumental earthquakes (1900-2012).

\begin{tabular}{lccc}
\hline Method & $\begin{array}{c}\text { Number } \\
\text { of clusters } \\
\text { of remaining } \\
\text { events } \\
\text { after } \\
\text { declustering }\end{array}$ & $\begin{array}{c}\text { Percent } \\
\text { of } \\
\text { independent } \\
\text { events }\end{array}$ \\
\hline $\begin{array}{l}\text { Reasenberg } \\
\text { (min. } \\
\text { parameters) }\end{array}$ & 393 & 9131 & $9.1 \%$ \\
$\begin{array}{l}\text { Reasenberg } \\
\text { (max. } \\
\text { parameters) }\end{array}$ & 583 & 7788 & \\
$\begin{array}{l}\text { Conjugate } \\
\text { windows } \\
\text { (this study) }\end{array}$ & 711 & & \\
\hline
\end{tabular}

Table 9. Results of declustering the unified earthquake catalog of Iran containing 10,043 events. Minimum and maximum values of parameters in Reasenberg [1985] method proposed by Van Stiphout et al. [2012].

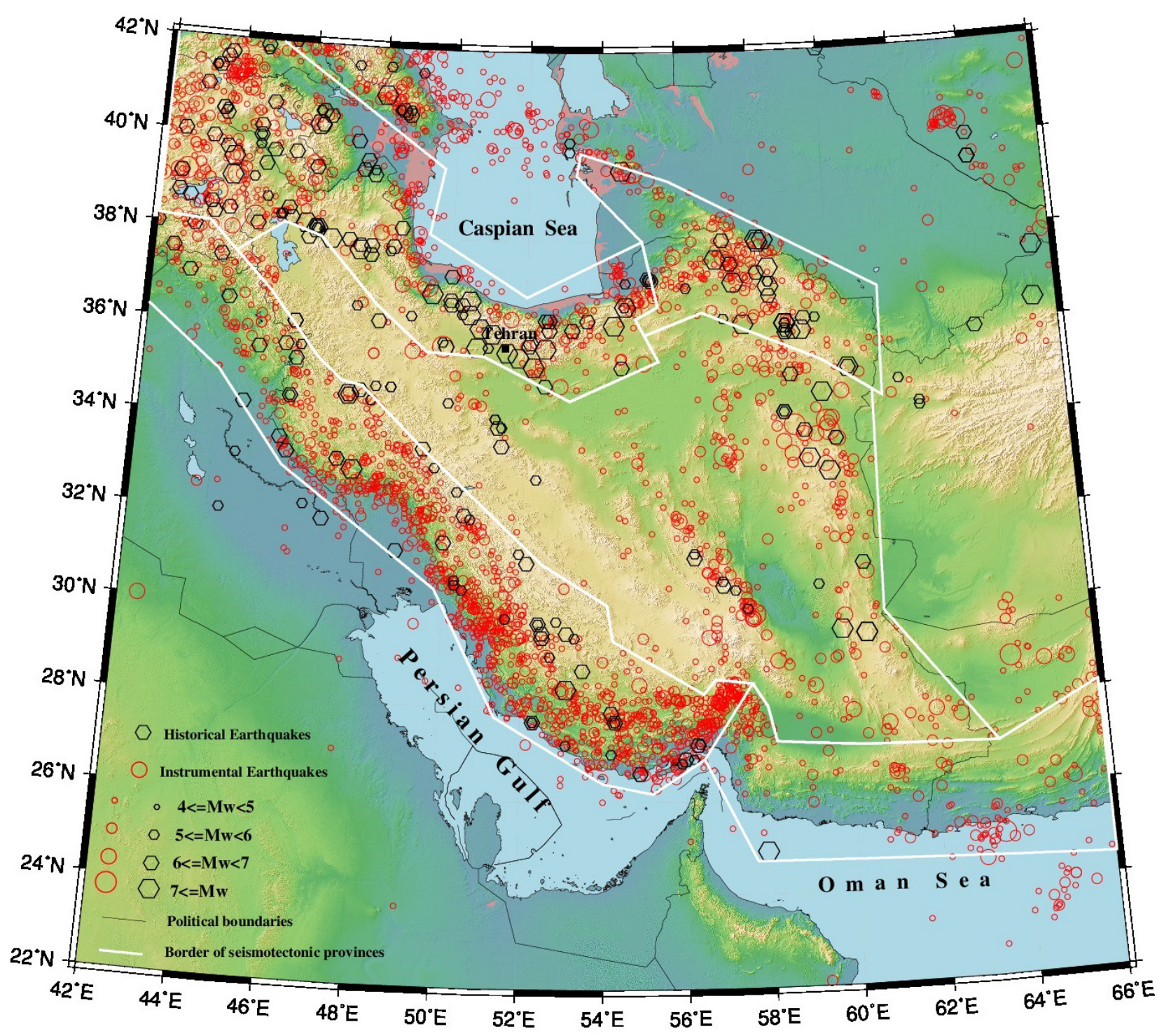

Figure 12. Epicenter distribution of historical (pre-1900) and declustered earthquakes (1900-2012) in Iran and the adjacent regions. 


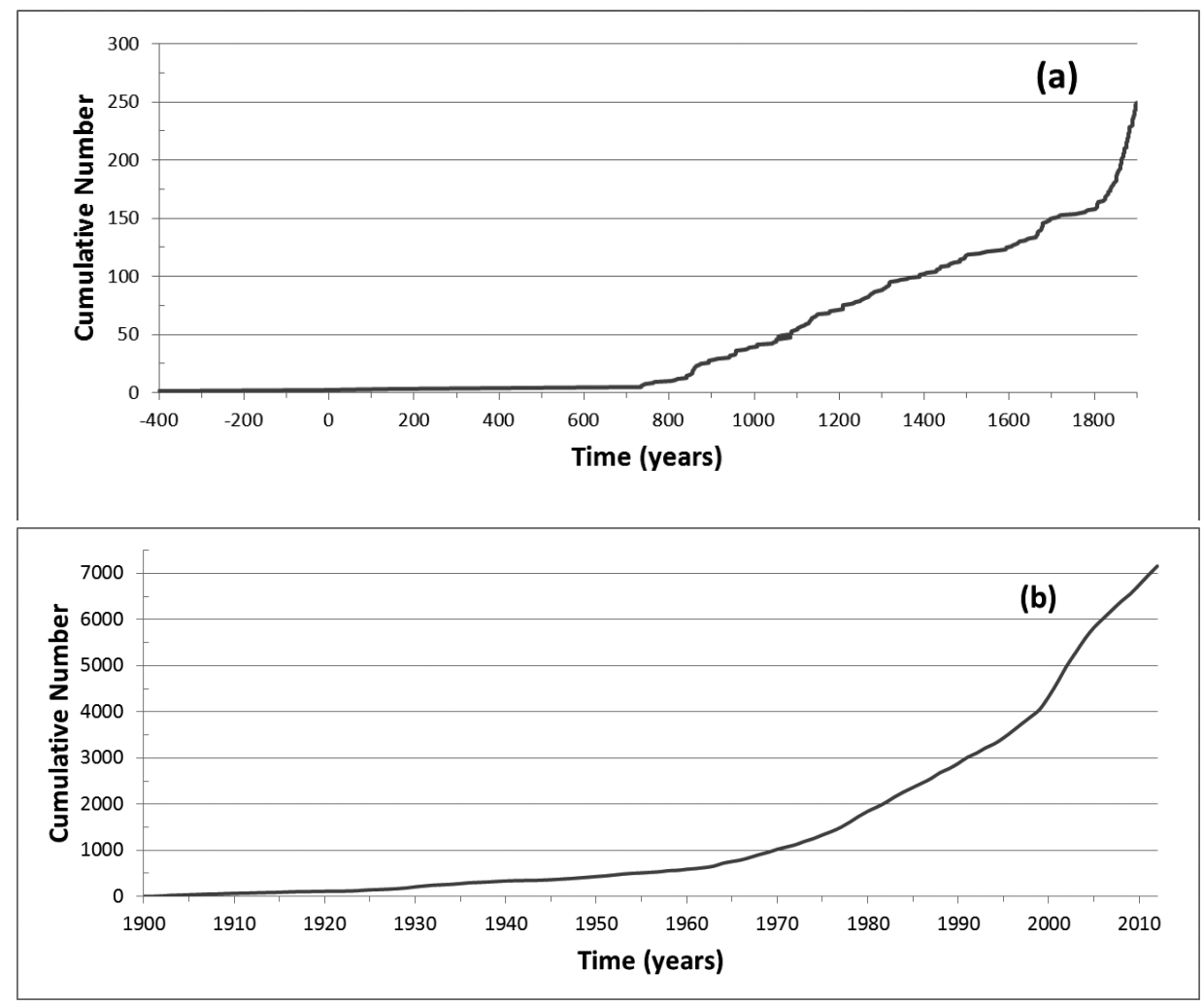

Figure 13. Cumulative numbers of historical (a) and instrumental (b) earthquakes versus time.

The final declustered catalog is provided in the electronic Supplement (2).

\section{Completeness of the catalog}

Unified and complete earthquake catalog is the main resource to determine seismicity parameters and analysis of seismic hazard in each region. Due to inadequacy in seismic station density, large earthquakes were recorded more completely. There are spatial and temporal incomplete parts in the catalog. It is noteworthy that incompleteness affects the parameter evaluations of Gutenberg and Richter [1944] relation.

The typical seismic event catalog can be divided into two parts. The first part contains only the largest historic events which occurred over a period of a few hundred years while the second part contains instrumental data for a relatively short period of time, with varying periods of completeness [Kijko 2011]. Although, the oldest evidences of events in Iran go back to 3rd millennium B.C. [Ambraseys and Melville 1982], adequate indications of individual events go back as far as the 7th century A.D. [Seyed-Nabavi 1978, Ambraseys and Melville 1982]. Figure 13a shows cumulative number of historical earthquakes in the catalog from 4 th century B.C. to 19 th century for which magnitudes are assigned and Figure 13b shows cumulative number of earthquakes after 1900 in the catalog. The time duration in Figure 13a can be divided into three intervals: 1) before 800 ,2) $800-1800$ and 3) 19th century. The mag- nitude of completeness $M_{c}$ in each seismotectonic province for data after 1900 is determined by EMR method, through ZMAP package, in three time intervals; early instrumental time-period (1900-1963), modern instrumental time period till 1995 (1964-1995), and from establishment of local networks in the country by IRSC (from 1996). Figures 14 to 16 show a set of graphs illustrating cumulative and noncumulative frequencymagnitude distributions for the five seismotectonic provinces of Iran and the total one for the three time intervals and results are summarized in Table 10. There are significant variations of $\mathrm{M}_{\mathrm{c}}$ in seismotectonic provinces. For example, $M_{c}$ for $C E$ differs from $M_{c}$ for KD about 0.9 magnitude units in early instrumental time-period (Figure 14). The results of completeness tests on the catalog indicate that, earthquakes with $\mathrm{M}_{\mathrm{w}}<4$ are incomplete, in all provinces for all times.

Variation of $\mathrm{M}_{\mathrm{c}}$ with time for instrumental time period (1900-2012) is shown in Figure 17. Increasing the slope in period 1998 to 2005, in Figure 15, and decreasing the $M_{c}$ in the same period, in Figure 17, is due to ETHZ data and also converting $\mathrm{M}_{\mathrm{N}}>3.5$ to $\mathrm{M}_{\mathrm{w}}$ by relation 14. As expected, the $M_{c}$ decreases with development of regional and local seismic stations.

\section{Results and conclusion}

In this study, the most complete unified and declustered catalog of earthquakes occurred before 2013, attributed to Iran and neighboring regions (the 

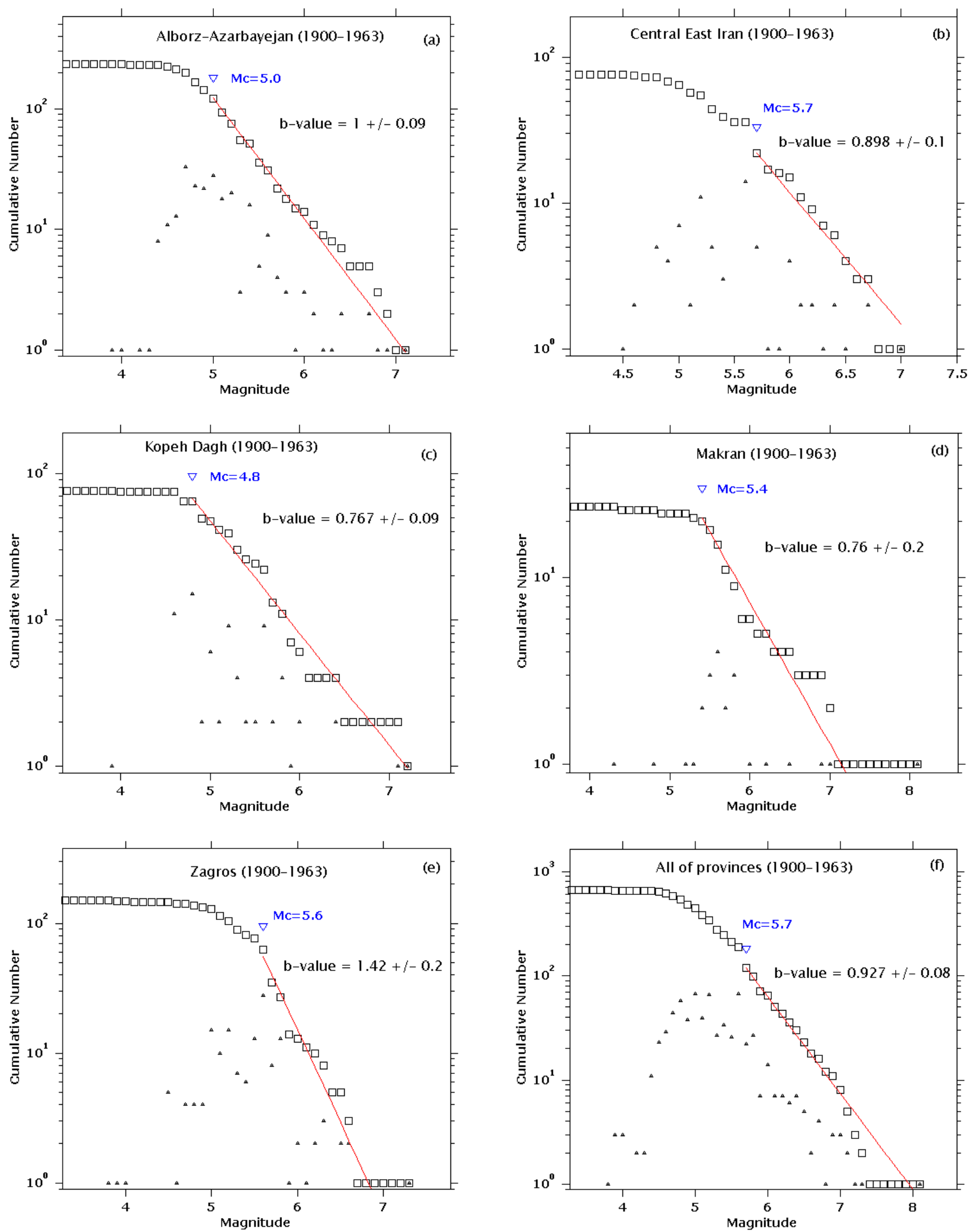

Figure 14. Magnitude of completeness $M_{c}$ and $b$-value for time interval 1900-1963 by using EMR method for the declustered catalog in major seismotectonic provinces in Iran and the total one.

area bounded in $22^{\circ}-42^{\circ} \mathrm{N}$ and $42^{\circ}-66^{\circ} \mathrm{E}$ ) is compiled. This catalog provides a reliable source to evaluate seismicity parameters and seismic hazard. Uncertainties of magnitude scales are estimated using the variance of difference between magnitude pairs. The variance ratio
( $\eta$ ) of each pair magnitude is calculated. Magnitude conversion relations $\mathrm{m}_{\mathrm{b}}-\mathrm{M}_{\mathrm{s}}, \mathrm{m}_{\mathrm{b}}-\mathrm{M}_{\mathrm{w}}, \mathrm{M}_{\mathrm{L}}-\mathrm{M}_{\mathrm{w}}, \mathrm{M}_{\mathrm{s}}-\mathrm{M}_{\mathrm{w}}$ for $M_{s} \leq 6.1$ and $M_{s} \geq 6.2$ and two $M_{N}-M_{w}$ relations for two time intervals (1996 to 2005 and 2006 to 2012) are defined, for the five major seismotectonics of Iran, 

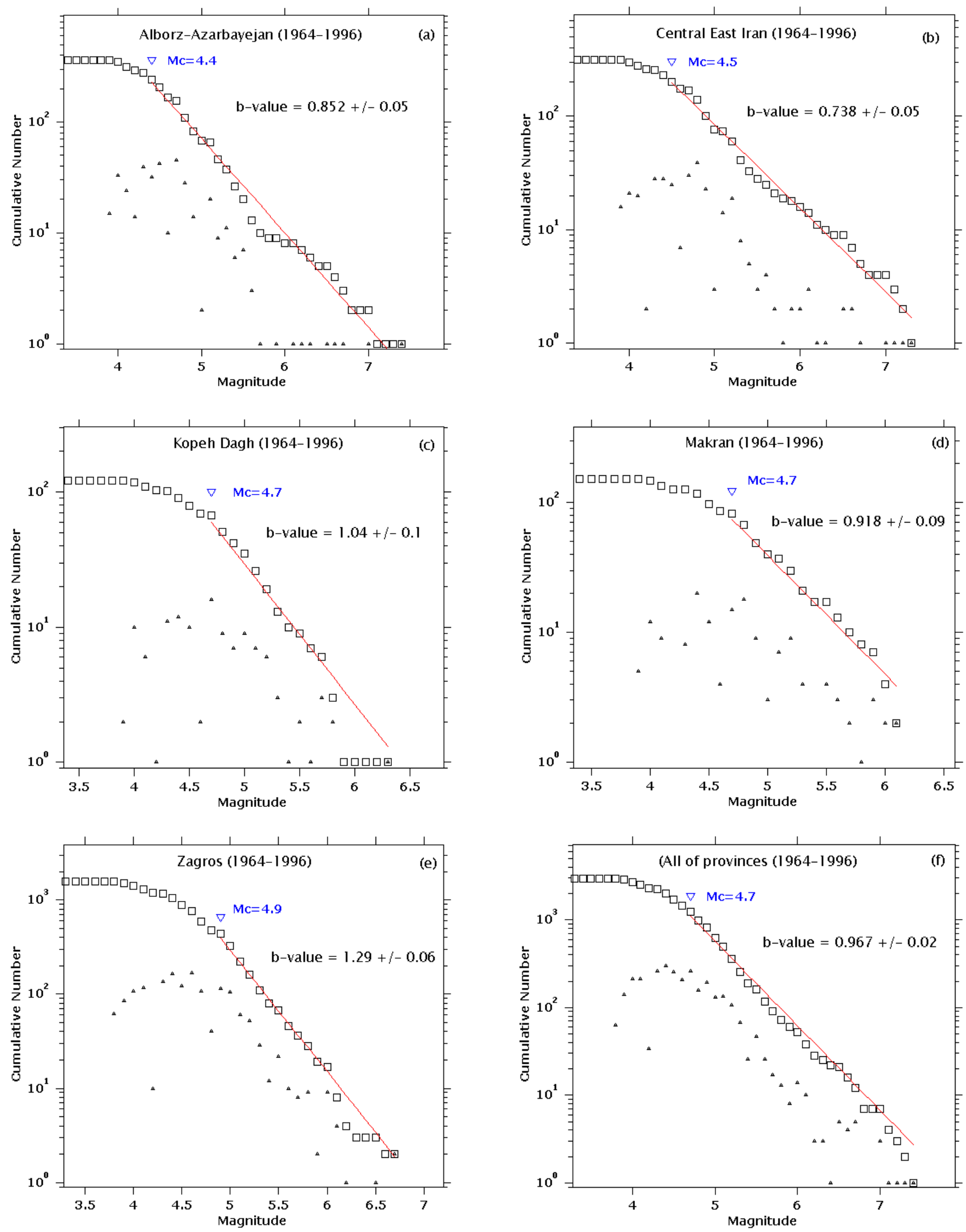

Figure 15. As Figure 14 for time interval 1964-1996.

using GOR method with the estimated $\eta$. The one-way analysis of variance (ANOVA) and the Tukey Honest Significant Difference (HSD) test are used to specify the significant differences between the magnitude conversion relations for the five regions. Data sets with signifi- cant differences are distinguished based on statistical tests. The catalogs are unified to $\mathrm{M}_{\mathrm{w}}$ and $\mathrm{M}_{\mathrm{s}}$ using the inferred conversion relations. The result is a catalog with 10,043 events including summary of origin times, longitude, latitude, depth, magnitudes, the uncertainty of 

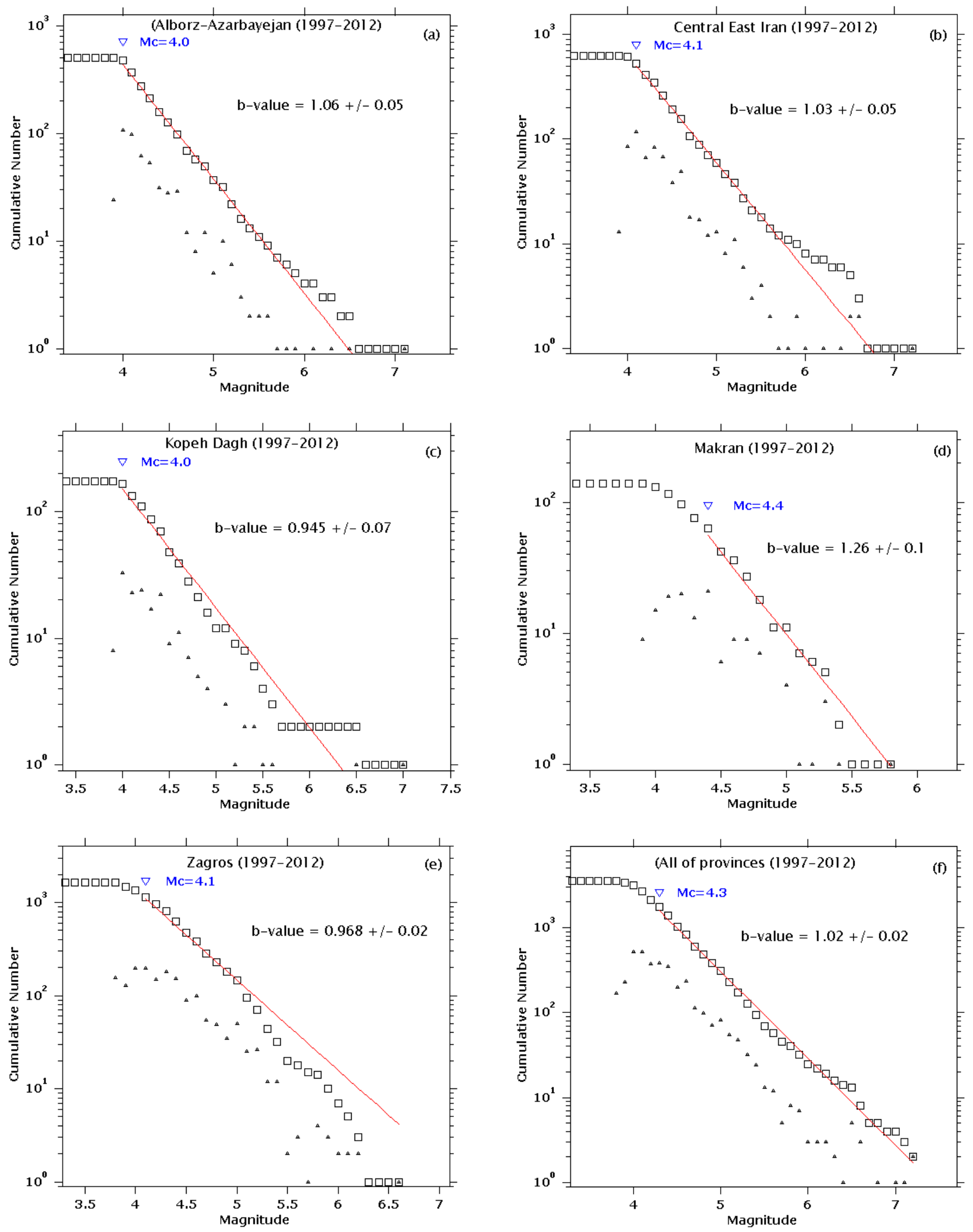

Figure 16. As Figure 14 for time interval 1997-2012.

reported or converted $\mathrm{M}_{\mathrm{w}}$ and references for each event.

Comparison between derived regressions in this study with the ones in Shahvar et al. [2013] and in Karimiparidari et al. [2013] reveals slight differences between conversion relations for $m_{b}-M_{s}, m_{b}-M_{w}, M_{s}-M_{w}$ and $\mathrm{M}_{\mathrm{L}}-\mathrm{M}_{\mathrm{w}}$, and further difference between $\mathrm{M}_{\mathrm{N}}-\mathrm{M}_{\mathrm{w}}$ for the period of 1996 to 2005 (Figure 10). It seems that, the main origin of the above mentioned differences is due to difference in their regression method; the GOR method with the relevant estimated $\eta$ in this study and 


\begin{tabular}{lccc}
\hline $\begin{array}{l}\text { Seismotectonic } \\
\text { province }\end{array}$ & $1900-1963$ & $1964-1996$ & $1997-2012$ \\
\hline Alborz-Azarbayejan & 5.0 & 4.4 & 4.0 \\
Central-East Iran & 5.7 & 4.5 & 4.1 \\
Kopeh Dagh & 4.8 & 4.7 & 4.0 \\
Makran & 5.4 & 4.7 & 4.4 \\
Zagros & 5.6 & 4.9 & 4.1 \\
All of provinces & 5.7 & 4.7 & 4.3 \\
\hline
\end{tabular}

Table 10. Magnitude of completeness $\left(\mathrm{M}_{\mathrm{c}}\right)$ for instrumental earthquakes in each and all major seismotectonic provinces of Iran in three time intervals.

the OR method in the other studies and the other origin is difference in their strategies to separate the data sets.

Declustering the unified catalog is carried out using two methods, conjugate distance-time windows and the cluster method [Reasenberg 1985]. Comparison between results of two methods in some aftershock sequences leads us to use conjugate distance-time windows method. A number of 2630 earthquakes (about $26.2 \%$ of data) were made out as dependent events. The declustered catalog contains 7413 independent events.

Magnitudes of completeness $M_{c}$ for the three time intervals after 1900 are determined by the EMR method. The $M_{c}$ decreases with development of local and regional seismic stations. The results of completeness tests on the catalog indicate that, earthquakes with $\mathrm{M}_{\mathrm{w}}<4$ are incomplete in all times. There are significant differences between $M_{c}$ in seismotectonic provinces. The unified and declustered catalogs are provided in electronic supplements.

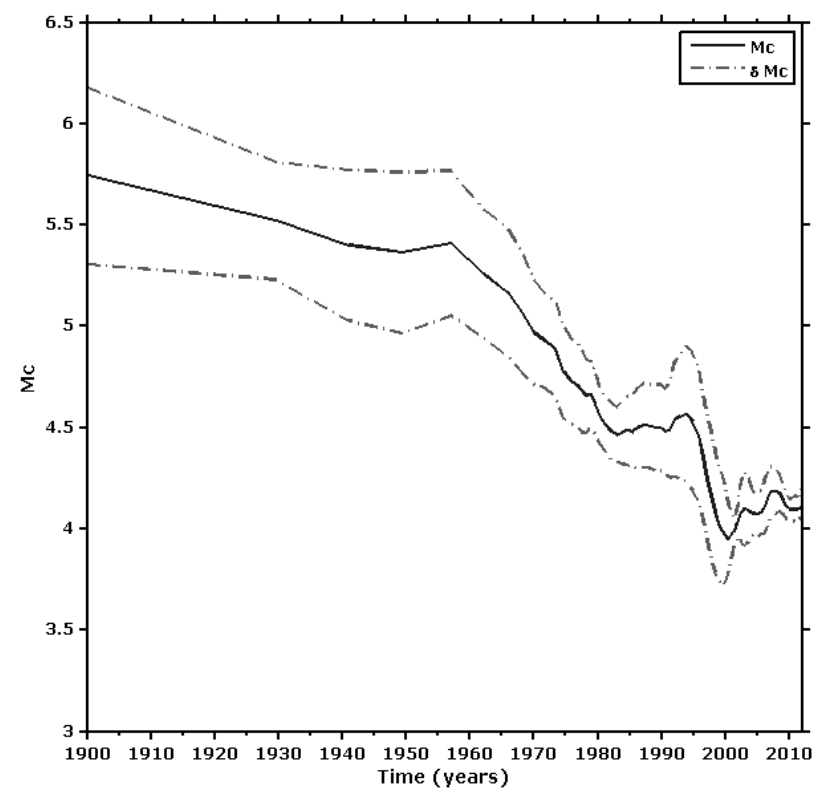

Figure 17. Variations of magnitude of completeness $\left(\mathrm{M}_{\mathrm{c}}\right)$ with time for instrumental earthquakes in Iran.
Acknowledgements. The authors gratefully thank Francesca Bianco and Andrea Bizzarri and the anonymous referees for the constructive comments, which significantly improved this article. The authors also would like to acknowledge the financial support of University of Tehran for this research under grant number 6201025.1.09.

\section{Data and sharing resources}

BPEI: Basic Parameters of Earthquakes in Iran (http: / / irsc.ut.ac.ir/BPEI.php, last accessed April 2013).

EHB: A revised version of the ISC Bulletin based on the algorithm of Engdahl et al. [1998] (http: / / www.isc. ac.uk/ehbbulletin/search/, last accessed April 2013).

ETHZ: Eidenössische Technische Hochschule Zurich (ETHZ) Regional MT catalog from 1999 to 2006 [Braunmiller et al. 2002] (http: / / www.seismo.ethz. ch, last accessed May 2013).

GCMT: HRVD CMT is presently addressed as GCMT earthquake data bulletins. It spans from 1976 to few months before the present [Dziewonski et al. 1981, Ekström et al. 2012] (http: / / www.globalcmt.org/ CMTsearch.html, last accessed April 2013).

IIEES: International Institute of Earthquake Engineering and Seismology (http:/ / www.iiees.ac.ir/iiees / EQsearch/EventQuery.aspx, last accessed April 2014).

IRSC: The Iranian Seismological Center (http: / irsc.ut. ac.ir/bulletin.php, last accessed May 2013).

ISC: International Seismological Center. On-line ISC Bulletin, http:/ / www.isc.ac.uk, Internat. Seis. Cent., Thatham, United Kingdom. (last accessed April 2014).

NEIC: National Earthquake Information Center of the US Geological Survey (USGS), the Preliminary Determinations of Epicenter catalog (PDE) from this agency http:/ / earthquake.usgs.gov/ earthquakes/ search/, last accessed April 2014).

\section{References}

Abdi, F., N. Mirzaei and E. Shabani (2013). Ground-motion scenarios consistent with PSH deaggregation for Tehran, capital city of Iran, Nat. Hazard Earth Sys., 13, 679-688.

Allen, M.B., M. Kheirkhah, M.H. Emami and S.J. Jones (2011). Right-lateral shear across Iran and Kinematic change in the Arabia-Eurasia collision zone, Geophys. J. Int., 184, 555-574.

Ambraseys, N.N. (1968). Early earthquakes in north central Iran, B. Seismol. Soc. Am., 58, 85-496.

Ambraseys, N.N., and A. Moinfar (1973). The seismicity of Iran. The Silakhor (Luristan) earthquake of 23rd January 1909, Annali di Geofisica, 26 (4), 659-678.

Ambraseys, N.N., A. Moinfar and F. Peronaci (1973). The seismicity of Iran. The Farsinaj (Kermanshah) earthquake of 13 December 1957, Annali di Geofisica, 26 (4), 679-692. 
Ambraseys, N.N. (1974a). The historical seismicity of North-Central Iran, Geol. Surv. Iran Rep., 28, 47-96. Ambraseys, N.N. (1974b). The seismicity of Iran. The Silakhor (Luristan) earthquake of 23rd January 1909 (Part II), Annali di Geofisica, 27 (3/4), 399-427.

Ambraseys, N.N., and A. Moinfar (1974a). The seismicity of Iran. The Firuzabad (Nehavend) earthquake of 16th August 1958, Annali di Geofisica, 27 (1/2), 1-21.

Ambraseys, N.N., and A. Moinfar (1974b). The seismicity of Iran. The Karkhaneh (Kangavar) earthquake of 24 March 1963, Annali di Geofisica, 27 (1/2), 23-36.

Ambraseys, N.N., and A. Moinfar (1975). The seismicity of Iran. The Turshiz (Kashmar) Khorassan earthquake of 25 September 1903, Annali di Geofisica, 28 (2/3), 253-269.

Ambraseys, N.N. (1976). Earthquake epicenters in Iran, Proc. CENTO Semin. Recent Advances in Earthquake Hazard Minimization, Tehran, 70-80.

Ambraseys, N.N. (1978). The relocation of epicenters in Iran, Geophys. J. R. Astr. Soc., 53, 117-121.

Ambraseys, N.N., and C.P. Melville (1982). A history of Persian earthquakes, Cambridge University Press, Cambridge.

Ambraseys, N.N. (1988). Engineering seismology, Earthq. Eng. Struct. Dyn., 17, 1-105.

Ambraseys, N.N. (2001). Reassessment of earthquakes, 1900-1999, in the eastern Mediterranean and the Middle East, Geophys. J. Int., 145, 471-485.

Ashtari, M. (2007). Time independent seismic hazard analysis in Alborz and surrounding area, Nat. Hazards, 42, 237-252.

Baker, C., J. Jackson and K. Priestley (1993). Earthquakes on the Kazerun line in the Zagros mountains of Iran: Strike-slip faulting within a fold-and-thrust belt, Geophys. J. Int., 115, 41-61.

Berberian, M. (1977). Macroseismic epicenters of Iranian earthquakes, Geol. Surv. Iran, Rep., 40, 79-99.

Berberian, M. (1981). Active faulting and tectonics of Iran, In: H.K. Gupta and F.M. Delany (eds.), ZagrosHindukush-Himalaya Geodynamics Evaluation, AGU, Washington, D.C., 33-69.

Berberian, M. (1994). Natural hazards and the first earthquake catalogue of Iran, Vol. 1: Historical hazards in Iran prior to 1900, IIEES, Tehran, Iran, 603.

Berberian, M. (1995). Master 'blind' thrust faults hidden under the Zagros folds: active basement tectonics and surface morphotectonics, Tectonophysics, 241, 193-224.

Berberian, M., and R.S. Yeats (1999). Patterns of historical earthquake rupture in the Iranian Plateau, B. Seismol. Soc. Am., 89, 120-139.
Berberian, M. (2005). The 2003 Bam urban earthquake: A predictable seismotectonic pattern along the western margin of the rigid Lut Block, southeast Iran, Earthq. Spectra, 2, S35-S99.

Berberian, M., and R. Walker (2010). The Rudb r Mw 7.3 earthquake of 1990 June 20 ; seismotectonics, coseismic and geomorphic displacements, and historic earthquakes of the western High-Alborz, Iran, Geophys. J. Int., 182, 1577-1602.

Berberian, M. (2014). Earthquakes and Coseismic Surface Faulting on the Iranian Plateau. A Historical, Social and Physical Approach, Series: Developments In Earth Surface Processes, 17 (Series eds.: J.F. Shroder Jr and B.V. Elsevier), Amsterdam, The Netherlands.

Bethmann, F., N. Deichmann and P.M. Mai (2011). Scaling relations of local magnitude versus moment magnitude for sequences of similar earthquakes in Switzerland, B. Seismol. Soc. Am., 101, 515-534; doi: $10.1785 / 0120100179$.

Bonini, M., G. Cortib, D. Sokoutisc, G. Vannuccid, P. Gasperinie and S. Cloetinghc (2003). Insights from scaled analogue modelling into the seismotectonics of the Iranian region, Tectonophysics, 376, 137-149.

Bormann, P., and J.W. Dewey (2012). The new IASPEI standards for determining magnitudes from digital data and their relation to classical magnitudes, In: P. Bormann (ed.), New Manual of Seismological Observatory Practice 2 (NMSOP-2), Potsdam, Deutsches GeoForschungsZentrum GFZ, 1-44; doi:10.2312/ GFZ.NMSOP-2_IS_3.3.

Braunmiller, J., U. Kradolfer, M. Baer and D. Giardini (2002). Regional moment tensor determination in the European-Mediterranean area-initial results, Tectonophysics, 356, 5-22.

Byrne, D.E., L.R. Sykes and D.M. Davis (1992). Great thrust earthquakes and aseismic slip along the plate boundary of the Makran subduction zone, J. Geophys. Res., 97, 449-478.

Castellaro, S., F. Mulargia and Y.Y. Kagan (2006). Regression problems for magnitudes, Geophys. J. Int. 165, 913-930.

Castellaro, S., and P. Bormann (2007). Performance of different regression procedures on the magnitude conversion problem, B. Seismol. Soc. Am., 97, 11671175.

Cosentino, P., V. Ficara and D. Luzio (1977). Truncated exponential frequency-magnitude relationship in the earthquake statistics, B. Seismol. Soc. Am., 67, 1615-1623.

Das, R., H.R. Wason and M.L. Sharma (2011). Global regression relations for conversion of surface wave and body wave magnitudes to moment magnitude, Nat. Hazards, 59, 801-810. 
Das, R., H.R. Wason and M.L. Sharma (2012). Temporal and spatial variations in the magnitude of completeness for homogenized moment magnitude catalog for northeast India, J. Earth. Syst. Sci., 121, 19-28.

Das, R., H.R. Wason and M.L. Sharma (2013). General Orthogonal Regression Relations between BodyWave and Moment Magnitudes, Seismol. Res. Lett., 84, 219-224.

Djamour, Y., P. Vernant, R. Bayer, H.R. Nankali, J.F. Ritz, J. Hinderer, Y. Hatam, B. Luck, N. Le Moigne, M. Sedighi and F. Khorrami (2010). GPS and gravity constraints on continental deformation in the Alborz mountain range, Iran, Geophys. J. Int., 183, 1287-1301.

Dziewonski, A.M., T.A. Chou and J. Woodhouse (1981). Determination of earthquake source parameters from waveform data for studies of global and regional seismicity, J. Geophys. Res., 86, 2825-2852.

Ekström, G., M. Nettles and A.M. Dziewonski (2012). The global CMT project 2004-2010: Centroid-moment tensors for 13,017 earthquakes, Phys. Earth Planet. In., 200/201, 1-9.

Engdahl, E.R., R. van der Hilst and R. Buland (1998). Global teleseismic earthquake relocation with improved travel times and procedures for depth determination, B. Seismol. Soc. Am., 88, 722-743.

Fuller, W.A. (1987). Measurement Error Models, John Wiley, New York.

Gardner, J.K., and L. Knopoff (1974). Is the sequence of earthquakes in southern California, with aftershocks removed, Poissonian?, B. Seismol. Soc. Am., 64, 1363-1367.

Gasperini, P., B. Lolli, G. Vannucci and E. Boschi (2012). A comparison of moment magnitude estimates for the European-Mediterranean and Italian regions, Geophys. J. Int., 190, 1733-1745; doi:10.1111/j.1365246X.2012.05575.x.

Gasperini, P., B. Lolli and G. Vannucci (2013). Empirical calibration of local magnitude data sets versus moment magnitude in Italy, B. Seismol. Soc. Am., 103, 2227-2246; doi:10.1785/ 0120120356.

Gasperini, P., and B. Lolli (2014a). Comment on 'Magnitude conversion problem using general orthogonal regression' by H.R. Wason, Ranjit Das and M.L. Sharma, (Geophys. J. Int., 190, 1091-1096), Geophys. J. Int., 196, 626-627; doi:10.1093/gji/ggs077.

Gasperini, P., and B. Lolli (2014b). Comment on 'General Orthogonal Regression Relations between Body-Wave and Moment Magnitudes' by Ranjit Das, H.R. Wason, and M.L. Sharma, Seismol. Res. Lett., 85, 351; doi:10.1785/0220130096.

Grünthal, G., R. Wahlström and D. Stromeyer (2009).
The unified catalogue of earthquakes in central, northern, and northwestern Europe (CENEC) updated and expanded to the last millennium, J. Seismol., 13, 517-541; doi:10.1007/s10950-008-9144-9.

Grünthal, G., and R. Wahlström (2012). The EuropeanMediterranean earthquake catalogue (EMEC) for the last millennium, J. Seismol., 16, 535-570.

Gutenberg, B., and C.F. Richter (1944). Measurement Error Models, B. Seismol. Soc. Am., 34, 185-188.

Hanks, T., and H. Kanamori (1979). A moment magnitude scale, J. Geophys. Res., 84, 2348-2350.

Hessami, K., F. Jamali and H. Tabasi (2003). Major active faults of Iran. 1:2,500,000, International Institute of Earthquake Engineering and Seismology, Tehran, Iran.

Hollingsworth, J., J. Jackson, R. Walker, M. Gheitanchi and M. Bolourchi (2006). Strike-slip faulting, rotation, and along-strike elongation in the Kopeh Dagh mountains, NE Iran. Geophys. J. Int., 166, 1161-1177.

Huang, W.Q., W.X. Li and X.F. Cao (1994). Research on the completeness of earthquake data in the Chinese mainland (1)-North China, Acta Seismologica Sinica, 7, 351-359.

Jackson, J., and D. McKenzie (1984). Active tectonics of the Alpine-Himalayan belt between western Turkey and Pakistan, Geophys. J. Int., 77, 185-264.

Jackson, J., M. Bouchon, E. Fielding, G. Funning, M. Ghorashi, D. Hatzfeld, H. Nazari, B. Parsons, K. Priestley, M. Talebian, M. Tatar, R. Walker and T. Wright (2006). Seismotectonic, rupture-process, and earthquake-hazard aspects of the 26 December 2003 Bam, Iran, earthquake, Geophys. J. Int., 163, 90-105.

Kagan, Y.Y. (2003). Accuracy of modern global earthquake catalogs, Phys. Earth Planet. In., 135, 173-209.

Kanamori, H. (1977). The energy release in great earthquakes, J. Geophys. Res., 82, 2981-2987.

Karimiparidari, S., M. Zare, H. Memarian and A. Kijko (2013). Iranian earthquakes, a uniform catalog with moment magnitudes, J. Seismol., 17, 897-911.

Karnik, V. (1969). Seismicity of the European Area, Part 1, Seismicity of Europe and the Mediterranean, Acad. Sc. Czech Rep., Geophys. Inst., Reidel, Dordrecht, The Netherlands, 28 pp.

Kasahara, K. (1985). Earthquake Mechanics, Cambridge, Cambridge University Press, 248.

Kijko, A. (2011). Introduction to Probabilistic Seismic Hazard Analysis (Extended version of contribution by A. Kijko, Encyclopedia of Solid Earth Geophysics, Harsh Gupta (ed.), Springer.

Knopoff, L., Y.Y. Kagan and R. Knopoff (1982). b Values for foreshocks and aftershocks in real and simulated earthquake sequences, B. Seismol. Soc. Am., 72, 1663-1676. 
Krystek, M., and M. Anton (2007). A weighted total least-squares algorithm for fitting a straight line, Meas. Sci. Technol., 22, 3438-3442.

Lay, T., and T.C. Wallace (1995). Modern Global Seismology, Academic Press, San Diego.

Lolli, B., and P. Gasperini (2012). A comparison among general orthogonal regression methods applied to earthquakes magnitude conversions, Geophys. J. Int., 190, 1135-1151; doi:10.1111/j.1365-246X.2012. 05530.x.

Masson, F., J. Chery, D. Hatzfeld, J. Martinoid., P. Vernant, F. Tavakoli and M. Ghafory Ashtiani (2005). Seismic versus aseismic deformation in Iran inferred from earthquake sand geodetic data, Geophys. J. Int., 160, 217-226.

Mirzaei, N., M. Gao and Y.T. Chen (1997). Evaluation of uncertainty of earthquakes parameters for the purpose of seismic zoning of Iran, Earthquake Research in China, 11, 197-212.

Mirzaei, N., M. Gao and Y.T. Chen (1998). Seismic source regionalization for seismic zoning of Iran: major seismotectonic provinces, J. Earthq. Pred. Res., 7, 465-495.

Mirzaei, N., M. Gao and Y.T. Chen (1999). Delineation of potential seismic sources for seismic zoning of Iran, J. Seismol., 3, 17-30.

Mirzaei, N., M.R. Gheitanchi, S. Naserieh, M. Raeesi, Z. Zarifi and S.G. Tabaei (2002). Basic parameters of earthquakes in Iran, Danesh Negar Publications, Tehran, 183 pp; available at http: / / irsc.ut.ac. ir/BPEI.php.

Mirzaei, N., E. Shabani and S.H. Mousavi (2014). Comment on "A Unified Seismic Catalog for the Iranian Plateau (1900-2011)" by Mohammad P. Shahvar, Mehdi Zare, and Silvia Castellaro, Seismol. Res. Lett., 85, 179-183.

Moinfar, A. (1976). The importance of macroseismic studies of past earthquakes, Proc. CENTO Semin. Recent Advances in Earthq. Hazard Minimizatian, Tehran, 65-69.

Mousavi-Bafrouei, S.H., N. Mirzaei, E. Shabani and M. Eskandari-Ghadi (2014). Seismic hazard zoning in Iran and estimating peak ground acceleration in provincial capitals, J. Earth and Space Phys., 40 (4), 15-38 (in Persian with English summary).

NIST/SEMATECH (2012). e-Handbook of Statistical Methods, accessed December 26, 2012, at http: / / w ww.itl.nist.gov/div898/handbook/.

Nuttli, O.W. (1973). Seismic wave attenuation relations for eastern North America, J. Geophys. Res., 78, 876-855.

Oncel, A.O., and O. Alptekin (1999). Effect of aftershocks on earthquake hazard estimation: An exam- ple from the North Anatolian fault zone, Nat. Hazards, 19, 1-11.

Peláez, J.A., M. Chourak, B.A. Tadili, L. Aït Brahim, M. Hamdache, C. López Casado and J.M. Martínez Solares (2007). A catalog of main Moroccan earthquakes from 1045 to 2005, Seismol. Res. Lett., 78, 614-621.

Poirier, J.P., and M.A. Taher (1980). Historical seismicity in the Near and Middle East, North Africa, and Spain from Arabic documents (VIIth-XVIIIth century), B. Seismol. Soc. Am., 70, 2185-2201.

Priestley, K., C. Baker and J. Jackson (1994). Implications of earthquake focal mechanism data for the active tectonics of the south Caspian basin and surrounding regions, Geophys. J. Int., 118, 111-141.

Reasenberg, P. (1985). Second-order moment of Central California seismicity 1969-1982, J. Geophys. Res., 90, 5479-5495.

Reiter, L. (1990). Earthquake Hazard Analysis, New York, Colombia University Press, 254 pp.

Rezapour, M. (2005). Magnitude scale in the Tabriz seismic network, J. Earth and Space Phys., 31 (1), 13-21 (in Persian with English summary).

Rydelek, P.A., and I.S. Sacks (1989). Testing the completeness of earthquake catalogs and the hypothesis of self-similarity, Nature, 337, 251-253.

Savage, M.K., and D.M. DePolo (1993). Foreshock probabilities in the western Great-Basin Eastern Sierra Nevada, B. Seismol. Soc. Am., 83, 1910-1938.

Scordilis, E.M. (2006). Empirical global relations converting $\mathrm{M}_{\mathrm{S}}$ and $\mathrm{m}_{\mathrm{b}}$ to moment magnitude, J. Seismol., 10, 225-236.

Seyed-Nabavi, M. (1978). Historical earthquakes in Iran, c. 300 B.C. -1900 A.D., J. Earth and Space Phys., 7, 70-117.

Shahvar, M.P., M. Zare and S. Castellaro (2013). A Unified Seismic Catalog for the Iranian Plateau (19002011), Seismol. Res. Lett., 84, 233-249.

Shearer, P.M. (2009). Introduction to Seismology, Cambridge University Press, Cambridge.

Smith, G.L., L. McNeill, K. Wang and J. He (2013). Thermal structure and megathrust seismogenic potential of the Makran subduction zone, Geophys. Res. Lett., 40, 1-6.

Stromeyer, D., G., Grünthal and R. Wahlström (2004). Chi-square regression for seismic strength parameter relations, and their uncertainties, with applications to an Mw based earthquake catalogue for central, northern and northwestern Europe, J. Seismol., 8, 143-153.

Tahernia, N., M. Khodabin and N. Mirzaei (2011). Mixed model for interoccurrence times of earthquakes based on the expectation-maximization algorithm, 
Acta Geophys., 59, 872-890.

Tahernia, N., M. Khodabin, N. Mirzaei and M. Eskandari-Ghadi (2012). Statistical models of interoccurrence times of Iranian earthquakes on the basis of information criteria, J. Earth Syst. Sci., 121, 463-474.

Taylor, D.W.A., J.A. Snoke, I.S. Sacks and T. Takanami (1990). Nonlinear frequency-magnitude relationship for the Hokkaido corner, Japan, B. Seismol. Soc. Am., 80, 340-353.

Taylor, J.R. (1997). An Introduction to Error Analysis: The Study of Uncertainties in Physical Measurements, University Science Books, 2nd ed., 327 pp.

Tchalenko, J.S., and J. Braud (1974). Seismicity and structure of the Zagros (Iran): the Main Recent Fault between $33^{\circ}$ and $35^{\circ}$ N, Philos. T. Roy. Soc. A, A227, 1-25.

Uhrhammer, R.A. (1986). Characteristics of northern and central California seismicity, Earthquake Notes, 57, p. 21 (abstract).

Utsu, T. (2002). Relationships between magnitude scales, In: W.H.K. Lee, H. Kanamori, P.C. Jennings and C. Kisslinger (eds.), International Handbook of Earthquake and Engineering Seismology, Academic Press, Amsterdam, 733-746.

Van Stiphout, T., J. Zhuang and D. Marsan (2012). Seismicity declustering. Community online resource for statistical seismicity analysis; doi:10.5078/ corssa52382934; available at http: / / www.corssa.org.

Vere-Jones, D. (1992). Statistical Methods for the Description and Display of Earthquake Catalogs, In: A. Walden and P. Guttorp (eds.), Statistics in the Environmental and Earth Sciences, 220-246.

Vernant, P., F. Nilforoushan, D. Hatzfeld, M.R. Abbassi, C. Vigny, F. Masson, H. Nankali, J. Martinod, A. Ashtiani, R. Bayer, F. Tavakoli and J. Chéry (2004). Present-day crustal deformation and plate kinematics in the Middle East constrained by GPS measurements in Iran and northern Oman, Geophys. J. Int., 157, 381-398.

Walker, R., and J. Jackson (2004). Active tectonics and late Cenozoic strain distribution in central and eastern Iran, Tectonics, 23, TC5010; doi:10.1029/2003T C001529.

Walker, R.T., E.A. Bergman, J.R. Elliott, E.J. Fielding, A.R. Ghods, M. Ghoraishi, J. Jackson, H. Nazari, M. Nemati, B. Oveisi, M. Talebian and R.J. Walters (2013). The 2010-2011 South Rigan (Baluchestan) earthquake sequence and its implications for distributed deformation and earthquake hazard in southeast Iran, Geophys. J. Int., 193, 349-374.

Walpersdorf, A., I. Manighetti, Z. Mousavi, F. Tavakoli, M. Vergnolle, A. Jadidi, D. Hatzfeld, A. Aghamohammadi, A. Bigot, Y. Djamour, H. Nankali and M.
Sedighi (2014). Present-day kinematics and fault slip rates in eastern Iran, derived from 11 years of GPS data, J. Geophys. Res. Solid Earth, 119; doi:10.1002/ 2013JB010620.

Wason, H.R., R. Das and M.L. Sharma (2012). Magnitude conversion problem using general orthogonal regression, Geophys. J. Int., 190, 1091-1096.

Wiemer, S., and M. Wyss (2000). Minimum magnitude of completeness in earthquake catalogs, examples from Alaska, the western United States, and Japan, B. Seismol. Soc. Am., 90, 859-869.

Wiemer, S. (2001). A software package to analyze seismicity: ZMAP, Seismol. Res. Lett., 72, 373-382.

Wilson, A.T. (1930). Earthquakes in Persia, B. Sch. Orient. Afr. St., 6, 103-131.

Woessner, J., and S. Wiemer (2005). Assessing the quality of earthquake catalogues: Estimating the magnitude of completeness and its uncertainty, B. Seismol. Soc. Am., 95, 684-698.

Yazdani, A., and M. Kowsari (2011). Statistical prediction of the sequence of large earthquake in Iran, IJE TRANSACTIONS B: Applications, 24 (4), 325-336.

Ye, H., Y. Zhou, Q. Zhou, W. Yang, G. Chen and C. Hao (1993). Study on potential seismic sources for seismic zonation and engineering seismic hazard analysis in continental areas, In: Continental Earthquakes, IASPEI Publication Series for the IDNDR 3, 473-478.

Ye, H., G. Chen and Q. Zhou (1995). Study on the intraplate potential seismic sources, In: Proc. Fifth International Conf. Seismic Zonation, 2, Nice, France, 1424-1430.

Zafarani, H., and M. Soghrat (2012). Simulation of Ground Motion in the Zagros Region of Iran Using the Specific Barrier Model and the Stochastic Method, B. Seismol. Soc. Am., 102, 2031-2045.

Zare, M., H. Amini, P. Yazdi, K. Sesetyan, M.B. Demircioglu, D. Kalafat, M. Erdik, D. Giardini, M. Asif Khan and N. Tsereteli (2014). Recent developments of the Middle East catalog, J. Seismol., 18 (3); doi:10.1007/s10950-014-9444-1.

\footnotetext{
${ }^{\star}$ Corresponding author: Noorbakhsh Mirzaei, University of Tehran, Institute of Geophysics, Department of Earth Physics, Tehran, Iran; email: nmirzaii@ut.ac.ir.

(C) 2014 by the Istituto Nazionale di Geofisica e Vulcanologia. All rights reserved.
} 